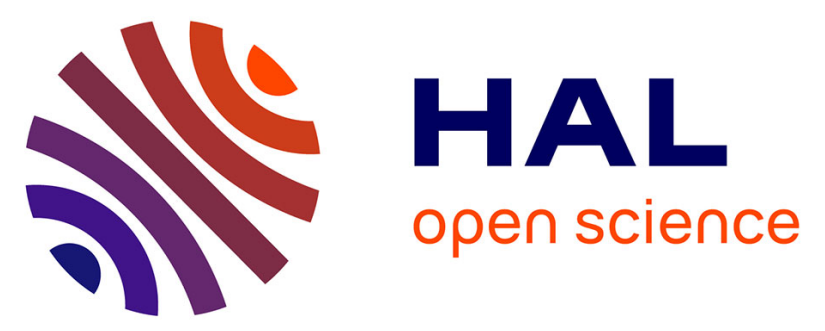

\title{
Biometals and glycosylation in humans: Congenital disorders of glycosylation shed lights into the crucial role of Golgi manganese homeostasis
}

François Foulquier, Dominique Legrand

\section{- To cite this version:}

François Foulquier, Dominique Legrand. Biometals and glycosylation in humans: Congenital disorders of glycosylation shed lights into the crucial role of Golgi manganese homeostasis. Biochimica et Biophysica Acta (BBA) - General Subjects, 2020, 1864 (10), pp.129674. 10.1016/j.bbagen.2020.129674 . hal-02997375

\section{HAL Id: hal-02997375 \\ https://hal.science/hal-02997375}

Submitted on 20 Nov 2020

HAL is a multi-disciplinary open access archive for the deposit and dissemination of scientific research documents, whether they are published or not. The documents may come from teaching and research institutions in France or abroad, or from public or private research centers.
L'archive ouverte pluridisciplinaire HAL, est destinée au dépôt et à la diffusion de documents scientifiques de niveau recherche, publiés ou non, émanant des établissements d'enseignement et de recherche français ou étrangers, des laboratoires publics ou privés. 
Biometals and glycosylation in humans : Congenital Disorders of homeostasis

${ }^{1}$ Univ. Lille, CNRS, UMR 8576 - UGSF - Unité de Glycobiologie Structurale et Fonctionnelle, F1059000 Lille, France

* Corresponding Author

Dominique Legrand (dominique.legrand@univ-lille.fr), Address : Univ. Lille, CNRS, UMR 8576

- UGSF - Unité de Glycobiologie Structurale et Fonctionnelle, F-59000 Lille, France.

Tel. + 33320434430 


\section{Abstract}

About half of the eukaryotic proteins bind biometals that participate in their structure and functions in virtually all physiological processes, including glycosylation. After reviewing the biological roles and transport mechanisms of calcium, magnesium, manganese, zinc and cobalt acting as cofactors of the metalloproteins involved in sugar metabolism and/or glycosylation, the paper will outline the pathologies resulting from a dysregulation of these metals homeostasis and more particularly Congenital Disorders of Glycosylation (CDGs) caused by ion transporter defects. Highlighting of CDGs due to defects in SLC39A8 (ZIP8) and TMEM165, two proteins transporting manganese from the extracellular space to cytosol and from cytosol to the Golgi lumen, respectively, has emphasized the importance of manganese homeostasis for glycosylation. Based on our current knowledge of TMEM165 structure and functions, this review will draw a picture of known and putative mechanisms regulating manganese homeostasis in the secretory pathway. manganese, TMEM165 


\section{Introduction}

Biometals are involved in a variety of biochemical processes ranging from cell signaling to maintenance of membrane potential, cell-cell adhesion, immune defense, cell energy supply, growth and development, protein folding, amino acid, lipid, protein and carbohydrate metabolisms, and glycosylation. Their activities not only rely on the so-called "metalloproteins", able to use them as cofactors to perform almost all biosynthesis and lytic redox reactions in metabolism, energy production and cell protection, but also on their carriers in biological fluids, and all molecular actors involved in their storage and transport in cells. This paper will first review the roles of biometals involved in human glycosylation processes, as well as their trafficking in fluids and cells. It will then focus on manganese (Mn), whose cellular homeostasis can be disturbed in Congenital Disorders of Glycosylation (CDG) patients presenting defects in specific membrane transporters. One of these transporters is TMEM165, whose recent findings revealed its crucial role in Golgi Mn homeostasis by controlling the overall glycosylation processes. From these findings, the review will draw the current picture of known and putative mechanisms governing Golgi Mn homeostasis and their impact on glycosylation.

\section{Focus on biometals influencing glycosylation : roles, trafficking and diseases}

2.1 Physiological importance of biometals involved in sugar metabolism and/or glycosylation

About two third of the periodic table consists of metals, among which the "biometals" refer to elements required in living organisms across every kingdom of life. These latter, belong to alkali metals (e.g. sodium ( $\mathrm{Na}$ ) and potassium $(\mathrm{K})$ ), alkali earth metals (e.g. magnesium $(\mathrm{Mg})$ and calcium (Ca)) and transition metals (e.g. manganese (Mn), iron (Fe), cobalt (Co), nickel $(\mathrm{Ni})$, copper $(\mathrm{Cu})$ and zinc $(\mathrm{Zn}))$. Many of these are found in huge amounts on earth, in the following order of abundance: Fe (6.3\%), Ca (5\%), Mg (2.9\%), $\mathrm{Na}(2.3 \%)$ and $\mathrm{K}(1.5 \%)$, whereas others are in much lower amounts, such as $\mathrm{Mn}$ (about $0.1 \%$ ) and $\mathrm{Ni}, \mathrm{Zn}, \mathrm{Cu}$, and $\mathrm{Co}$ (gathering $0.02 \%$ ) (from WebElements.com). Interestingly, the content in living organisms is globally proportional to the abundance of these elements in earth's crust : for example, the five major

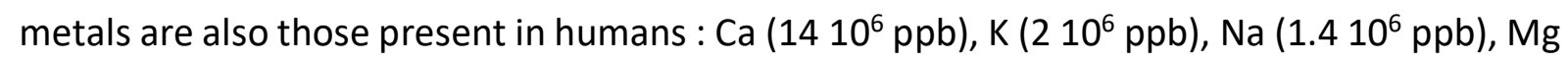


$\left(27010^{3} \mathrm{ppb}\right)$ and Fe (60 10 $\left.10^{3} \mathrm{ppb}\right)$. Prevalence amounts of Ca over Fe may easily be explained by the many structural roles played by $\mathrm{Ca}$ in cells and tissues, including of course bones, whereas Fe has chiefly functional roles. Except for $\mathrm{Zn}$, whose content ( $3310^{3} \mathrm{ppb}$ ) is close to $\mathrm{Fe}$, the other biometals are present in trace amounts : $\mathrm{Cu}\left(110^{3} \mathrm{ppb}\right), \mathrm{Mn}\left(0.210^{3} \mathrm{ppb}\right), \mathrm{Ni}$ (0.1 $\left.10^{3} \mathrm{ppb}\right)$ and Co (0.02 10 $\left.10^{3} \mathrm{ppb}\right)$ (WebElements.com).

Most biometals in eukaryotes are bound to about half of total proteins, among which $25-30 \%$ are proteins requiring metals as cofactors to function (so called "metalloproteins") [1]. For example, $4-10 \%$ of total eukaryotic proteins might be $\mathrm{Zn}$ metalloproteins. In addition, biometals may be coordinated in proteins by a large number of organic complexes, such as the heme groups in hemoglobin and cytochromes, and inorganic ligands like sulfides and oxides.

According to the literature, the main biometals serving as cofactors in the physiological processes of eukaryotes are $\mathrm{Ca}, \mathrm{Cu}, \mathrm{Zn}, \mathrm{Fe}, \mathrm{Mn}, \mathrm{Mg}, \mathrm{Ni}$ and $\mathrm{Co}$. Among these elements, only $\mathrm{Ca}, \mathrm{Mg}, \mathrm{Mn}, \mathrm{Zn}$ and $\mathrm{Co}$ are cofactors of human metalloproteins directly involved in sugar metabolism and/or glycosylation processes. The following sections will briefly review the general features and roles of those biometals in cell physiology.

2.1.1 Ca

$\mathrm{Ca}$, with a stable oxidation state of +2 , is the most abundant metal in eukaryotic cells [2]. This feature reflects both its lack of redox toxicity, unlike $\mathrm{Cu}, \mathrm{Fe}$ and $\mathrm{Mn}$, and its participation, like $\mathrm{Mg}$, to the structural stabilization of biomolecules and membranes, to protein-protein or sugar-protein interactions of members of the CAM (cellular adhesion molecules) families, and the catalytic activity of hundreds of enzymes.

It is difficult to find a physiological process that does not depend on $\mathrm{Ca}$. Ca indeed triggers new life at fertilization, controls several developmental processes, and during the differentiation process, Ca may also regulate diverse cellular processes such as metabolism, proliferation, secretion, contraction, synaptic transmission, learning and memory. In addition, $\mathrm{Ca}$ takes a special place in vertebrates whose bone matrix rigidity is given by Cahydroxyapatite [3]. Bone hence represents the main Ca storage organ of vertebrates. All organisms contain hundreds of Ca-binding molecules with very different affinities for the metal, and playing a plethora of functions. As reviewed in [4], these Ca-binding molecules are 
encompassed in several larger families including the EF-hand, EGF (Epidermal Growth Factor)like, GLA (gamma-carboxyglutamic acid-rich), C2-like and hemopexin protein domain families, and the annexins binding phospholipids. Many of them, including for example proteins involved in cell-cell adhesion and signaling (e.g. integrin $\beta 4$, C-type animal lectins, CAM proteins like cadherin and selectins, and proteoglycans), hydrolytic processes (e.g. proteases like trypsin and endonucleases, lipases like phospholipase A involved in inflammation, glycosidases, sulfatases and peroxidases) and protein folding and sorting in the secretory pathway (e.g. calnexin, calreticulin, BiP, calsequestrin, calumenin and Cab45) play important roles in structural organization and cohesion of cells and tissues, cell membrane and biomolecule trafficking, cell metabolism, muscle contraction, and cell signaling (Ca is indeed a crucial secondary messenger).

In the secretory pathway, where most glycosylation processes takes place, a sufficiently high luminal Ca concentration, ranging from up to $1 \mathrm{mM}$ (ER (endoplasmic reticulum)) to $0.1 \mathrm{mM}$ (trans-Golgi), is required, not only for glycosylation but also for normal protein synthesis, chaperone-dependent processing, sorting and casual cleavage of newly synthesized proteins [5]. The membrane/vesicle and protein trafficking in both directions (anterograde and retrograde) between the ER and the Golgi, and along the Golgi, actually highly depends on the Ca luminal concentration.

With specific regard to glycosylation, $\mathrm{Ca}$ is essential for the activity of hydrolytic enzymes : glycosidases and sulfatases. Ca indeed participates to the active site of class $1 \alpha 1-2$ mannosidases of GH family 47, such as the human ER $\alpha 1-2$ mannosidase (MAN1B1) and Golgi $\alpha-$ mannosidases MAN1A, MAN1B and MAN1C [6], and of the sulfatases involved in the

\subsection{2 $\mathrm{Mg}$ and $\mathrm{Mn}$}

$\mathrm{Mg}$ and $\mathrm{Mn}$ are metals with close chemical properties, allowing their substitution on many metalloproteins, but which differ in several aspects. Indeed, while Mg has a stable oxidation state of +2 and no redox activity, Mn has oxidation states ranging from +2 to +7 , among which +2 and +3 are the most stable in physiological conditions. This later thus plays important roles in redox mechanisms, most especially in the oxidative stress response of organisms. 

and membranes, it also participates to the activity of many enzymes through direct interactions with the enzyme itself, the enzyme substrate, or both [8,9]. The Lewis acidity of $\mathrm{Mg}$ (pKa 11.4) is indeed used to not only permit hydrolysis but also condensation reactions. Moreover, since ATP must be bound to $\mathrm{Mg}$ to biologically be active, $\mathrm{Mg}$ has a special place in these ATP-dependent reactions. Cellular Mg thus plays a crucial role in the stability of all polyphosphate compounds and their use in many enzymatic reactions aiming to hydrolyze phosphate esters (ATPases) and to transfer phosphoryl (kinases and phosphatases), in virtually every metabolic pathway [9]. Lastly, Mg was reported, like Ca and Zn (see next section), as a possible secondary messenger, more specifically in neuronal maturation [10].

Although the Mn concentration is much lower than that of $\mathrm{Mg}$ in human cells and tissues (see introduction of section 2.1), it plays crucial roles in many biological pathways. Indeed, $\mathrm{Mn}$ is a cofactor of oxidoreductases, transferases, hydrolases, lyases, isomerases and ligases, called "manganoproteins", necessary for metabolic functions and antioxidant responses [11]. Mn therefore plays crucial roles in host defense, cellular energy, blood clotting, reproduction, digestion, development and bone growth, fat and carbohydrate metabolism, glycosylation, blood sugar and pressure regulations, and neurotransmitter synthesis/metabolism. With regard to host defense, the primary role for $\mathrm{Mn}$ is to prevent the oxidative stress response by destroying free radicals, not only as a cofactor of the mitochondrial SODIl enzyme (Superoxide dismutase II), also known as MnSOD [12], but also surprisingly by forming simple salts and complexes (e.g. Mn2+-phosphate or Mn2+-carboxylates) [13]. Nevertheless, the physiological significance of such non-enzymatic reactions is not known, and somehow contradictory to the deleterious effects of $\mathrm{Mn}$ accumulation observed in Mn-exposed workers suffering of manganism and neurodegenerative diseases. In addition, it has been shown that several signaling pathways involved in immune modulation, such as the inflammatory NF-kB pathway [14] and mTOR signaling [15], are responsive to $\mathrm{Mn}$. It is however currently not known how $\mathrm{Mn}$ regulates those signaling pathways. With regard to metabolism, and apart from the roles of $\mathrm{Mn}$ in sugar and carbon metabolism and glycosylation, reported in the next paragraph, the metal plays an important role in nitrogen metabolism and neurotransmission, as a cofactor of glutamine synthetase catalyzing the conversion of glutamate, a neurotransmitter in animals, and ammonia to form glutamine [16]. Lastly, $\mathrm{Mn}$ is involved in several aspects of host 
physiology and integrity in animals. $\mathrm{Mn}$ is indeed necessary to the activity of mammalian Xprolylaminopeptidase catalyzing degradation of bradykinin, a blood pressure regulator peptide and inflammatory mediator [17]. It increases wound healing via activation of matrix metalloproteinase (MMP)-2 and -9 [18], two enzymes that are also necessary in maintaining bone integrity by processing bone components such as type-1 collagen [19]. Interestingly, the Mn2+/ATP-dependent Golgi casein kinase (e.g. FAM20C) that phosphorylates secretory pathway proteins within Ser-x-Glu/pSer motifs also plays a key role in biomineralization of bones and teeth by phosphorylating proteins such as AMELX (amelogenin), AMTN (amelotin), ENAM (enamelin) and SPP1 (osteopontin) [20]. Finally, Mn was also reported to participate to the maintenance of genome stability in activating the Mre11 nuclease complex [21].

The rationale to gather $\mathrm{Mg}$ and $\mathrm{Mn}$ in a common paragraph of this review lies in their roles as co-factors for glycosyltransferases (GTs), the key enzymes of glycosylation processes, as well as in some enzymes of sugar metabolism, all referenced in the Carbohydrate-Active enZYmes database (http://www.cazy.org/). The catalytic reaction involved in all the different glycosylation types are indeed performed by GTs, about 250 in the Golgi, which can be classified according to their folding (reviewed in [22]). In humans, where GTs have been best characterized, they are classified into two families : GTs with a GT-A fold consisting of a $\alpha / \beta / \alpha$ sandwich resembling a Rossmann domain and generally having a DXD motif, and GTs with a GT-B fold with two Rossmann-like domains without any DXD motif, such as the $\alpha-1,6$ fucosyltransferase. Interestingly, the DXD motif of the GT-A family is known to coordinate nucleotide sugars via divalent metals, usually Mn or Mg [22]. The metal plays a role of Lewis acid catalyst that facilitates the release of the nucleoside diphosphate group by electrostatically stabilizing the developing negative phosphate charge. It has to be noted that, in certain metal-independent GTs like sialyltransferases and the $\beta-1,6-$ GlcNAc transferase from the GT-A family, tyrosyl hydroxyls or basic amino acids are used instead of divalent metals to electrostatically stabilize substituted phosphate leaving groups. Although the "natural" metal co-factor ( $\mathrm{Mn}$ or $\mathrm{Mg}$ ) has not been clearly identified in all eukaryotic GTs, since many of them are able to use both metals in in vitro conditions, there are evidences that most human GT-A enzymes use preferentially $\mathrm{Mn}$ as cofactor, such as : $\beta$-1,4-galactosyltransferase 1 [23] (N-glycosylation) ; polypeptide $\mathrm{N}$ - acetylgalactosaminyltransferases 1, 2, 3 and 10 [24] (mucin-type O-glycosylation) ; $\beta$-1,4-glucuronyltransferase 1 [25] and LARGE xylosyl- and 
glucuronyltransferase 1 and 2 [26] (O-mannosylation) ; xyloside xylosyltransferase 1 [27] (Oglucosylation); fucosyltransferase 3 [28], $\beta-1,4-\mathrm{N}$-acetylgalactosaminyltransferase 2 [29], $\alpha-1,3-\mathrm{N}$-acetylgalactosaminyltransferase and $\quad \alpha 1,3$-galactosyltransferase [30] (Oglycosylation); xylosyltransferase 1 [31], $\beta$-1,3-glucuronyltransferase 1 and 3 [32, 33] and $\beta$ 1,4-galactosyltransferase $7 \quad[34] \quad$ (glycosaminoglycans synthesis) ; $\beta-1,3-\mathrm{N}$ acetylgalactosaminyltransferase [35] (glycolipids). Other GTs may use preferentially Mg or both $\mathrm{Mg}$ and $\mathrm{Mn}$ interchangeably such as : $\alpha 1-3$-fucosyltransferase 7 [36] (O-glycosylation) ; $\beta$-1,4-galactosyltransferase 6 [37] (glycolipids) ; N-acetylglucosaminyl transferases I, II and III [38] and dolichyl-phosphooligosaccharide-protein glycotransferase (OST) (N-glycosylation) [22]. Among these enzymes, the $\beta$-1,4-galactosyltransferase 1 metal requirement has been particularly well characterized [23]. The enzyme possesses two metal-binding sites, one that exclusively binds $\mathrm{Mn} 2+$ with a high affinity and the other one that binds a variety of metals including $\mathrm{Ca}$, Zn, Co, Fe and $\mathrm{Cd}$. In others GTs, either Ca or Co may also substitute $\mathrm{Mn}$ or $\mathrm{Mg}$ as cofactors : UDP-Glucose glycoprotein glucosyltransferase 1 and 2 [39] (N-glycoprotein folding) and the glucuronyltransferase activity of the LARGE xylosyl-and glucuronyltransferase 1 [40] (mucin-type O-glycosylation) for $\mathrm{Ca}$, and the chondroitin sulfate 1-3 (proteoglycan synthesis) for Co [32, 33].

With regard to the roles of $\mathrm{Mg}$ and $\mathrm{Mn}$ in sugar and carbon metabolisms, both metals are cofactors of the mitochondrial pyruvate carboxylase catalyzing transformation of pyruvate to oxaloacetate in the Krebs cycle and carbohydrate metabolism [41], and the phosphoenolpyruvate carboxykinase (PEPCK) converting oxaloacetate into phosphoenolpyruvate and carbon dioxide [42]. They thus play crucial roles in gluconeogenesis and lipogenesis, biosynthesis of neurotransmitters, and glucose-induced insulin secretion by pancreatic cells. Mg also participates to the activity of hexokinases forming hexose phosphate (e.g. glucose-6-phosphate) [43], and also of hexose and hexosamine phosphatases (e.g. glucose 3 phosphatase) and dehydrogenases [8]. Finally, other Mn-dependent enzymes involved in carbon metabolism are the phosphoglycerate mutases [44] and arginases such as ARG1 and ARG2 human isoforms in cytosol and mitochondria, respectively, catalyzing the hydrolysis of arginine to ornithine in the urea cycle [45].

\subsection{3 $\mathrm{Zn}$ and Co}


Although $\mathrm{Zn}$ has a stable oxidation state of +2 in physiological conditions and is not redox active, unlike $\mathrm{Fe}$ and $\mathrm{Cu}$, it participates to the catalytic sites of hundreds of proteins. Furthermore, like $\mathrm{Ca}$ and $\mathrm{Mg}$, it is essential for the structure of many molecules, most particularly as a structural cofactor in zinc fingers of many proteins. Finally, $\mathrm{Zn}$ has been evidenced, like $\mathrm{Ca}$, as a potential second messenger in breast cancer cells, lymphocytes and mast cells [46]. Zn thus plays crucial roles in defense and immunity, signaling and neurotransmission, vesicular trafficking, development, metabolism, gene regulation, chromatin and protein structure (reviewed in [47]).

Co is a divalent (common oxidation state) or trivalent transition metal. The importance of this

2.2 Trafficking of biometals in cells and organisms

\subsubsection{Presence of metals in extracellular fluids}

Among the biometals within the scope of this review, Ca possesses by far the highest concentration in human biological fluids, such as plasma : Ca $(2 \mathrm{mM})>\mathrm{Mg}(0.5 \mathrm{mM})>>\mathrm{Fe}(20$ $\mu \mathrm{M})>\mathrm{Zn}(17 \mu \mathrm{M})>\mathrm{Cu}(8-24 \mu \mathrm{M})>>\mathrm{Mn}(100 \mathrm{nM})>\mathrm{Ni}(40 \mathrm{nM})>>$ Co $(25 \mathrm{pM})[2]$.

Since $\mathrm{Ca}$ is highly soluble in physiological conditions and forms complexes with fast exchange rates, about half $\mathrm{Ca}$ in the plasma is present in free ionized form, while the remaining is mainly bound to plasmatic proteins (mostly albumin) and in a much lesser extent (about 5\%) in 
complexes with small anions such as bicarbonate, citrate and lactate [53]. Extracellular $\mathrm{Mg}$, accounting for about $1 \%$ of total body $\mathrm{Mg}$, is primarily found in serum, like $\mathrm{Ca}$, either free, bound to plasma proteins or complexed to anions such as phosphate, bicarbonate and citrate, and red blood cells [8].

To the opposite of both $\mathrm{Ca}$ and $\mathrm{Mg}$, but like Fe, $\mathrm{Zn}$ is certainly the biometal whose solubility is the most critical in physiological conditions. Hence, $\mathrm{Zn}$ is present in blood plasma bound to proteins such as albumin (about 70\%), $\alpha 2$-macroglobulin and transferrin, the major Fe3+ carrier in blood [54].

Finally, with regard to $\mathrm{Mn}$ and $\mathrm{Co}$, while both elements may exist in multiple oxidation state, their divalent state is stable and dominant in aqueous conditions. Mn does not exhibit high

\subsubsection{Storage of biometals in cells and organisms}

Storage of biometals within cells and organisms may be required for several purposes. First is the storage of metals with signaling functions (e.g. Ca). Second purpose is the safe storage of rare metals acting as enzymes' cofactors, in energy production chains, and/or structurally important for the functions of many classes of biomolecules. Third purpose is sequestration and buffering of intrinsically toxic metals (e.g. $\mathrm{Cd}$ or $\mathrm{Hg}$ ) or metals in excess for their further elimination from cells and organisms. Fourth purpose is related to the defense of host cells against pathogens, either by taking away rare metals from pathogens or by using those metals against pathogens. For the three last purposes, storage systems may allow cellular accumulation of metals while avoiding toxicity. To comply with these requirements, metal may be stored using specific molecular systems and/or cellular compartmentalization (nucleus, mitochondria, secretory pathway_compartments and endosomes).

Together with ferritins for Fe storage, the metallothioneins are major metal storage and detoxification molecules of $\mathrm{Zn}$, but also $\mathrm{Cu}, \mathrm{Cd}$ and $\mathrm{Hg}$ [58]. They are small cysteine-rich 
intracellular and extracellular proteins (500 to $14000 \mathrm{Da})$ that bind metals-with high-affinity but also high lability.

Owing to its signaling properties and contractile functions, $\mathrm{Ca}$ is subject to a tightly regulated storage in intracellular compartments, mostly those from the secretory pathway but also in mitochondria. The main Ca storage compartment is the ER/SR_(sarcoplasmic reticulum), but it was also demonstrated that Golgi is also important for Ca storage [59]. Up to 5\% of the total cellular Ca was actually reported in the Golgi (130-300 $\mu \mathrm{M})$. Interestingly, most of Ca within the lumen of the secretory pathway is not in the free form but complexed to several molecular systems, thus avoiding the efflux transporters to pump against a too high concentration gradient. In the SR, polymerized calsequestrin indeed binds up to $50 \mathrm{Ca}$ ions with moderate affinity [60], whereas chaperones involved in the correct folding and processing of $\mathrm{N}$ glycoproteins in the ER, such as calnexin and calreticulin (calregulin, CRP55, CaBP3, ERp60), similar to calsequestrin [61], and BiP (Binding Immunoglobulin Protein) [62], are also Cabinding proteins. Calreticulin indeed binds about $50 \%$ of $\mathrm{Ca}$ in the ER [63] while BiP may bind around $25 \%$ of the total store of resting cells [62]. Other luminal Ca-binding proteins have also been reported in ER and/or Golgi : reticulocalbin 1 and 2 (RCN2/Erc55), Cab45, calumenin, crocalbin/CBP50 and Erc55/RCN2 [64], as well as CALNUC (nucleobindin) [65] and p54/NEFA [66]. At last, cytosolic $\mathrm{Ca}$ also binds to buffer proteins such as parvalbumin and calbindin that play important roles in signaling by modulating local Ca concentrations [67]. This suggests that, in resting and normal conditions, $\mathrm{Ca}$ and most other metals are present in the cell organelles at moderate concentrations in the free form, and even much lower concentrations in the cytosol, especially if those elements are secondary messengers or harboring potential toxicity.

With regard to $\mathrm{Mn}$, the metal may localize at a micromolar range concentration in several cellular sites including mainly mitochondria, nucleus, Golgi and cytoplasm, in a way that depends on the cell type. For example, in neuronal cells, where Mn ions tend to accumulate, the metal was essentially found in the nucleus and in the cytosol [68]. In astrocytes and glia, accumulation mostly occurs in the cytosol, owing to the presence of significantly-high amounts of Mn-containing glutamine synthetase, and in mitochondria [69, 70]. At last, $\mathrm{Mn}$ was located within the Golgi of PC-12 dopaminergic cells at physiological concentrations, and accumulated in this organelle when environmental exposure to $\mathrm{Mn}$ was increased [71]. 
Estimated brain $\mathrm{Mn}$ ion concentrations, determined by neutron activation analysis and ICPMS, are in the range of 20-53 $\mu \mathrm{M}$ under physiological conditions [72]. However, whereas many chemical tools and techniques exist for tracking intracellular Mn [72], few data have been made available about the ratio between the pools of protein-bound and free $\mathrm{Mn}$ in cells. $\mathrm{Mn}$ content analysis of rat hepatocytes by Electron Paramagnetic Resonance (EPR) analysis indicated that free $\mathrm{Mn}$ did not exceed $2 \%$ of total Mn content [73].

\subsubsection{Membrane transporters incells-of biometals}

Transport of biometals, like all other ions, is driven by two sets of membrane transporters: the ion channels (membrane-spanning water-filled pores) and the active transporters (named porters in this review) which include carriers and pumps (reviewed in [74]). This section will briefly comment a list of the 83 membrane transporters of biometals involved in the glycosylation processes of mammals ( $\mathrm{Ca}, \mathrm{Mg}, \mathrm{Mn}, \mathrm{Zn}$ and $\mathrm{Co}$ ) and expressed in virtually all human tissues and cells (Table 1). They belong, in addition to the transferrin receptor system, to 14 channels and 12 porter families, listed in the Transporter Classification Database (TCBD, http://tcdb.org) approved by the International Union of Biochemistry and Molecular Biology (IUBMB). Only the transporters potentially regulating cellular $\mathrm{Mn}$ homeostasis will be described in more details in section 3.

Metals can diffuse passively through $\alpha$-type channels according to their concentration gradient, either freely or regulated by the membrane potential, extracellular or intracellular signals, mechanical or temperature stimuli [75]. Those proteins, which consist of transmembrane $\alpha$-helical spanners, actually participate in numerous cell functions. Unsurprisingly, like the well-characterized $\mathrm{Na}$ and $\mathrm{K}$ channels involved in cell signaling and the generation of action potentials in excitable cells, the Ca channels, which are involved in secondary cell signaling, molecular interactions and structure, largely predominate in the TCBD database. Indeed, among the 39 channels listed in Table 1, only four do not transport Ca (MMGT1 and MLKL are effective Mg channels whereas MagT1 and TUSC3 are putative Mg channels), and a strict specificity for Ca has been reported for 15 of them within 6 channel families : CRAC-C (Ca Release-activated Ca (CRAC) Channel), CaTA (Calcium Transporter A), Flower (Synaptic Vesicle-Associated Ca Channel), Presenilin (Presenilin ER Ca Leak Channel), RIR-CAC (Ryanodine-Inositol 1,4,5-triphosphate Receptor Ca Channel), and VIC (Voltage-gated 
Ion Channel). All other Ca channels have been reported as non-selective, thus potentially transporting other monovalent and divalent metals. This is the case for : Mg (3 channels in addition to MagT1 and MLKL : TRPM 2,6 and 7 of the TRP-CC (Transient Receptor Potential Caz+ Channel) family); Mn (TRPML1 (PCC (Polycystin Cation Channel) family), TRPM7 (TRP-CC family) and CACNA1H (VIC (Voltage-gated lon Channel) family)) ; Zn (TRPML1 and TRPM7). With the exception of VDAC 1-3, three mitochondrial Ca importers of the MPP (Mitochondrial and Plastid Porin) family, all metal channels are cytosolic influx transporters from the extracellular space or cell organelles.

Porters serve to transport metals against their concentration gradients in cells, therefore allowing their uptake in compartments requiring their functions, creating or maintaining the gradients, and/or allowing their elimination from cells [76]. They are hence highly strategic in controlling ion homeostasis in cell compartments. According to the Nernst equation, the active transport of ions in vertebrates requires energy from various sources, mostly ATP (primary active transport), or by symport or antiport of others ions (secondary active transport), issued most of the time from primary active transport. Within the TCBD, twelve families gathering 43 porters, in addition to the transferrin receptor (TFR), have been functionally characterized for $\mathrm{Ca}, \mathrm{Mg}, \mathrm{Mn}, \mathrm{Zn}$ or $\mathrm{Co}$ (Table 1). Specificity for a single metal was reported for about two third of these porters, mainly for Zn (8 porters from the CDF (Cation Diffusion Facilitator) family and 8 from the ZIP (Zinc -Iron Permease) family) but also for Mg (MMGT1 from the MMgT (Membrane Mg Transporter) family, 3 porters from the MgtE (Mgz+ Transporter-E) family and 3 from the NIPA (NIPA Mg Uptake Permease) family), for Ca (mitochondrial porter LetM1 and 3 porters from the P-ATPase (P-type ATPase) family), and for Mn (putative ER porter ATP13A1 from the P-ATPase family). All other porters were reported to have a broader specificity for metals, thus carrying two or more metals species. It is also of note that some porters, such as those from the CaCA (Ca:Cation Antiporter) family expressed

\subsection{Biometals and diseases} In humans, disturbances in metal homeostasis, mainly due to defective transporters but also to extreme environmental metal concentrations, are often associated with pathogenesis of 
many severe diseases, including neurodegenerative diseases, cancer, cardiovascular dysfunctions, and metabolic disorders (Table 2). Those disturbances may consist of either abnormally increased intracellular metal concentrations, causing deleterious redox effects of free metals and/or mismetallation, i.e. the exchange of a natural metal cofactor by another one on metalloproteins, or the shortage of a given metal cofactor in a cell compartment. This section will report the main diseases caused by metal homeostasis disturbances, with the exception of CDGs described in the next section.

Not only brain is the principal target for a number of toxic non-essential heavy metals causing protein mismetallation, such as aluminum, lead, lithium, mercury, tin and thallium, but, it also illustrates quite well the importance of $\mathrm{Mn}, \mathrm{Fe}, \mathrm{Zn}$ and Ca homeostasis [77] whose impairment is associated with severe pathologies (Table 2). For example, the Huntington's syndrome, a neurodegenerative disease mainly caused by the accumulation and clustering of an abnormal version of the huntingtin protein, may result in significantly lower levels of $\mathrm{Mn}$ in neuronal cells and the striatum [78]. Elsewhere, it has been reported that one of the hallmarks of Alzheimer's disease (AD) is an abnormal distribution of $\mathrm{Cu}, \mathrm{Fe}, \mathrm{Zn}$ and $\mathrm{Mn}$ in the frontal lobe of the brain, which is associated with memory [79]. Their accumulation, particularly Mn and $\mathrm{Fe}$, have been associated with several severe neuro-pathologies including AD and Parkinson's disease $(P D)[80,81]$. With regard to $M n$, manganism, caused in miners and welders by a chronic exposure to $\mathrm{Mn}$, brings a clear demonstration of the neurological troubles caused by Mn excess, resembling PD symptoms [82]. The neurotoxicity of $\mathrm{Mn}$ appears to be determined by its oxidation state, free $\mathrm{Mn3}+$ being more toxic than $\mathrm{Mn2}+$ and prone, like Fe3+, to generate reactive oxygen species (ROS) through the so-called Fenton chemistry. This participates in impaired dopaminergic, glutamatergic and $\gamma$-aminobutyric acid neuronal transmission, mitochondrial dysfunction, oxidative stress and neuroinflammation. Furthermore, the toxicity of high $\mathrm{Mn}$ concentrations is probably also due to interferences with the $\mathrm{Mg}$-binding sites of metalloproteins, compromising normal physiology, causing apoptosis and, in the case of parkinsonism, inhibiting tyrosine hydroxylation required for dopamine synthesis [83]. Interestingly, using the yeast model, it has been shown that $\mathrm{Mn}$ excess may induce mutations in the mitochondrial genome, most probably by either substituting $\mathrm{Mg}$ on the mitochondrial DNA polymerase or directly binding to DNA [84]. In addition, familial Mn-induced neurotoxicity may be caused by mutations in efflux transporters involved in detoxification of 
$\mathrm{Mn}$ at both systemic and cellular levels, such as SLC39A14 and SLC30A10 (ZnT10) in patients with the hypermanganesaemia with dystonia syndromes $1 \& 2[85,86]$. At the cellular level, it has indeed been reported that SLC30A10 mutations involved in PD result in Mn accumulation within the Golgi [87], hence altering trafficking of GPP130 and vesicles [88]. Moreover, the Kufor-Rakeb syndrome, a rare form of juvenile-onset PD, is caused by defects in the ATP13A2 (PARK9) P5B-ATPase, a transporter reported to play important roles in protecting cells against $\mathrm{Mn}$ cytotoxicity via regulating intracellular $\mathrm{Mn}$ homeostasis [89]. However, the very recent evidence that ATP13A2 is a polyamine transporter strongly demonstrates an indirect role of the protein in Mn homeostasis [90]. At last, a link could also exist between $\mathrm{Mn}$ homeostasis and PD through $\alpha$-synuclein, an unstructured protein that aggregates to form insoluble fibrils (Lewy bodies) in PD and synucleinopathies. Some studies indeed suggested that $\mathrm{Mn}$ and $\mathrm{Ca}$ could be regulators of synuclein-induced toxicity [91]. With regard to $\mathrm{Zn}$, whose release from presynaptic vesicles modulates both ionotropic and metabotropic post-synaptic receptors homeostasis, its altered homeostasis might be a risk factor for depression, $A D$, aging and other neurodegenerative disorders [92]. Indeed, $\mathrm{Zn}$ accumulation could promote mitochondrial dysfunction and further ROS generation. Furthermore, neurodegenerative disorders in humans may also be caused by Ca homeostasis imbalance due to deficient Na:Ca exchangers (NCX) involved in Ca extrusion [93], or to dysregulation of PSEN1 (presenilin-1), a passive ER leak channel [94].

Several diseases other than neuro-pathologies may be caused by impaired homeostasis of metals (Table 2). However, the molecular mechanisms leading to most of them are far from being known. With regard to $\mathrm{Ca}$, since intra-and extracellular metal levels are maintained at totally different concentrations and by different mechanisms, pathologies caused by $\mathrm{Ca}$ homeostasis imbalance are diverse [95]. For example, the familial hypocalciuric hypercalcemia (FHH) and neonatal severe hyperparathyroidism (NSHPT) are due to mutations in the Casensing receptor (CasR). CasR is also a sensor for $\mathrm{Mg}$ whose homeostasis is intimately linked to Ca homeostasis, and its deficiency leads to chronic diseases such as coronary heart disease, hypertension, diabetes, and asthma [96]. Furthermore, defects in Ca transporters are also responsible for well-identified diseases such as the Hailey-Hailey and Darier's diseases, two clinically and histologically-overlapping skin diseases caused by mutations in the Golgi protein ATP2C1 (SPCA1) and the ER protein ATP2A2 (SERCA2) genes, respectively [97, 98]. Impaired 
actin reorganization and abnormality in the desmosome-keratin filament complex, leading to keratinocyte adhesion abnormalities, were associated to defects in those transporters [99]. Interestingly, it was also shown that ATP2C1 could detoxify cytosolic Mn accumulation by transferring it into the secretory pathway $[5,100,101]$. With regard to $\mathrm{Zn}$, its cellular uptake through the plasma membrane is mainly controlled by two porter families : the ZIP and CDF families for $\mathrm{Zn}$ influx and efflux to and from the cytosol, respectively (Table 1). Interestingly, several defects in members of the ZIP family are associated with severe pathologies : Acrodermatitis enteropathica Zn-deficiency disease (ZIP4), carotid artery disease for SLC39A2 (ZIP2), metastasis in lymph nodes for SLC39A6 (ZIP6), Spondylocheiro dysplastic form of Ehlers-Danlos syndrome for SLC39A13 (ZIP13), metastasis of breast cancer for SLC39A10 (ZIP10) and probably Hyperostosis cranialis interna and bone homeostasis for SLC39A14 (ZIP14) [102]. Intriguingly, it was also reported that SLC39A5, A6 and A10 may be evolutionary precursors of prion proteins in mammals [103].

\subsection{CDGs caused by ion homeostasis defects}

Although almost $5 \%$ of the human genome is devoted to glycosylation, only a limited number of gene defects hampering the glycosylation processes have been characterized hitherto. More than 130 types of CDGs have actually been reported, whose gene defects virtually affect specific steps of N-glycosylation, O-glycosylation, glycosphingolipid and glycosylphosphatidylinositol anchor glycosylation, multiple glycosylation and other pathways such as the dolichol pathway.

CDGs are inherited rare diseases causing defective protein and/or lipid glycosylation in patients [104, 105]. The CDG patients exhibit an extremely variable phenotype, ranging from intellectual disability to severe multiorgan failure and death. Two categories of CDGs can be distinguished concerning protein N-glycosylation : type I CDGs (CDG-I) and type II CDGs (CDGII) $[106,107]$. Whereas CDG-I are characterized by the absence of $\mathrm{N}$-glycans on proteins, due to impaired assembly and/or transfer of the lipid-linked oligosaccharide (LLO) precursor GIc3Man9GIcNAc2-P-P-dolichol (G3M9Gn2-P-P-Dol) in the ER, CDG-II result from defects in genes coding proteins affecting directly or indirectly_protein glycans maturation, mainly in Golgi but also in ER. Most CDGs are caused by mutations in genes coding for enzymes directly involved in glycan assembly in both ER and Golgi, such as GTs, remodeling glycosidases, precursor synthesis enzymes and sugar-nucleotide transporters, but a large group of CDG now 
also includes proteins involved in Golgi structure and vesicular trafficking (COG (Conserved Oligomeric Golgi) proteins and VSP13B (Cohen syndrome)) as well as ion homeostasis [105]. Indeed, defective ion transporters in CDG patients have pointed out the importance of $\mathrm{pH}$ and biometal homeostasis in the maintenance of the glycosylation process. With regard to $\mathrm{pH}$, its regulation is essential for ensuring correct protein conformation, optimal enzyme activity and driving transport into organelles of nutrients and ions, including biometals. For example, metal transporters of the NRAMP (Metal Ion (Mn-Fe) Transporter) family, such as SLC11A1 (Nramp1) and SLC11A2 (DMT1/DCT1 or Nramp2) (Table 1), essential for homeostasis of Mn, $\mathrm{Fe}, \mathrm{Zn}$ and other metals, are symporters using the proton-motive force [108]. It is hence expected that any defects in ATPase proton pumps and proton exchangers is a serious hindrance to cell functions, including glycosylation. Several CDGs were actually identified and characterized with gene defects in the vacuolar (V-type) ATPase proton pump and accessory proteins: ATP6V0A2, ATP6AP1, ATP6AP2, ATP6V1E1, ATP6V1A, TMEM199 and CCDC115 [105]. They come in addition to other heritable pathologies due to defects in the V-ATPase complex, such as osteopetrosis, distal renal tubular acidosis and X-linked myopathy with excessive autophagy (reviewed in [109]). In ATP6VOA2-CDG, which represents the major pathology, defects affect the a2 subunit of the V0 domain V-ATPase and cause a cutis laxa type II phenotype, short limbs and wrinkly skin syndrome [110]. The mutations were shown to affect ATPase structure and assembly, Golgi trafficking, glycosylation and lysosomal functions, and leading to defects in extracellular matrix homeostasis and architecture [110]. As illustrated in Figure 1, the observed N-glycosylation defect in ATP6V0A2-CDG patients deals with the last steps of $\mathrm{N}$-glycan synthesis, galactosylation and sialylation, which take place in the trans-Golgi [110]. These glycosylation defects very likely result from a defect in Golgi pH regulation impairing enzymatic and sorting processes in the Golgi compartment [110].

Surprisingly, very few defective metal transporters have been evidenced in CDG patients. This suggests that, even if biometals are an absolute requisite for key molecular players of the glycosylation machinery, the broad specificity of a large panel of metal transporters may possibly compensate the deficiency of one of them. Furthermore, the possibility that the deficiency of a given transporter affects essential cellular pathways (e.g. metabolic and energy-producing pathways), in addition to glycosylation, and eventually leads to early death of patients makes difficult to classify such deficiency as a CDG. Until now, the sole effective 
metal transporters whose deficiencies have led to CDGs are TMEM165 [111] (CaCA2 (Ca:H+ Antiporter-2) family), and SLC39A8 (ZIP8) [112] (Table 1). Elsewhere, deficiencies in MagT1 and TUSC3, two members of the MAGT1 family described as potential Mg transporters, also caused CDGs $[113,114]$. Interestingly, the "X-linked immunodeficiency with Mg defect, EBV infection and neoplasia" (XMEN) disease, listed in Table 2, is characterized by defects in MagT1 and leads to chronic decrease in the intracellular basal level of free $\mathrm{Mg}$ and the abolition of the transient T-cell receptor (TCR)-induced $\mathrm{Mg}$ flux required for optimal T-cell activation [115]. However, with regard to the MAGT1 family members, the function of these proteins as Mg transporters remains unclear and doubtful. It is indeed well demonstrated that MagT1 and TUSC3 are mutually exclusive accessory proteins of the STT3B subunit of the ER Noligosaccharyltransferase (OST) complex involved in the transfer of lipid-linked oligosaccharide (LLO) structure (Glc3Man9GIcNAc2-Dol) to the asparagine residue in nascent polypeptides (reviewed in [116]). It has been hypothesized that if MagT1 or TUSC3 may interfere with $\mathrm{Mg}$ homeostasis, this could occur through an indirect mechanism involving STT3B complex-dependent glycosylation of a protein that is needed for $\mathrm{Mg}$ transport activity [116]. Therefore, only two biometal porters have been so far_clearly pointed out as important molecular determinants in the glycosylation processes : TMEM165, a Golgi/endosome Mn and/or Ca porter, and SLC39A8 (ZIP8), a plasma membrane Mn, Zn, Fe and Cd porter. Interestingly, the common denominator of these two porters is their involvement in $\mathrm{Mn}$ transport, Mn being a fundamental co-factor, together with $\mathrm{Mg}$, of a large number of Golgi GTs (see section 2.1.2), most especially the $\beta$-1,4-galactosyltransferase 1 involved in terminal $\mathrm{N}$-glycosylation (Fig. 1). This observation underlines the crucial role of Mn Golgi homeostasis in glycosylation whose known or putative mechanisms of regulation will be deciphered in the following section.

\section{Current understanding of the mechanisms regulating cellular $\mathrm{Mn}$ homeostasis}

From the 83 transporters listed in Table 1, a total of 16 proteins ( 3 channels, 12 porters and the TFR) have been described as effective or potential Mn transporters between all cellular compartments (referred in this review as $\mathrm{Mn}$ influx proteins when the metal is transferred from the extracellular space or organelles to the cytosol, and Mn efflux proteins when the metal is transported from the cytosol to the extracellular space or organelles), therefore underlining the apparent complexity of $\mathrm{Mn}$ fluxes in the cell and their regulations (Fig. 2). 
531 Notably, similar numbers of $\mathrm{Mn}$ influx (3 channels, 4 porters and TFR) and efflux (8 porters) transporters may be observed. The fact that dysregulation of any of these transporters may have a significant impact on glycosylation may be questioned, but it is now clear from CDGs studies that both SLC39A8 (ZIP8) and TMEM165, ensuring Mn influx and efflux respectively, are crucial. In order to draw the current picture of $\mathrm{Mn}$ homeostasis regulation impacting glycosylation, we will review the principal proteins involved in Mn membrane transport, with a special focus on TMEM165.

\subsection{Mn influx proteins}

In addition to channels TRPML1, TRPM7 and CACNA1H [117, 118], which are able to import $\mathrm{Mn}$ from the extracellular space or endosomes into the cytosol, together with $\mathrm{Ca}, \mathrm{Zn}, \mathrm{Mg}$, and/or Fe, five $\mathrm{Mn}$ influx transporters primarily expressed at the plasma membrane have been identified: SLC11A1 (NRAMP1) , SLC11A2 (DMT1/DCT1), SLC39A8 (ZIP8), SLC39A14 (ZIP14) and TFR [112, 119, 120] (Fig. 2). Although the relative importance of those porters in global Mn acquisition by cells has not been evaluated, and certainly depends on the cell type, this could be deduced from the impact of their defects in patients. With regard to SLC11A1 and SLC11A2 (NRAMP family), two metal:proton symporters whose mutations have been associated to infectious and chronic inflammatory diseases (e.g. Crohn's disease), and many neurodegenerative diseases such as AD and PD, respectively [108], it is difficult to discriminate between the deleterious effects due to impaired $\mathrm{Mn}$ homeostasis and those of other metals. Indeed, both proteins, and also of course TF, are strongly involved in Fe transport and metabolism. Whereas SLC11A1 is more selective for Mn2+ than Fe2+ [121], SLC11A2 exhibits highest selectivity for Fe2+ but is also selective for other metals, in the order $\mathrm{Zn2+>} \mathrm{Mn2+>}$ $\mathrm{Co} 2+>\mathrm{Ca} 2+>\mathrm{Cu} 2+>\mathrm{Ni2}+[122]$. However, SLC11A2 is generally considered as the predominant $\mathrm{Mn}$ importer, at both systemic and cellular levels. At the systemic level, $\mathrm{Mn}$ homeostasis is known to be mainly controlled by its intestinal absorption and its biliary excretion by liver $[123,124]$. In humans, ingested $\mathrm{Mn}$ (about 2-3\% of dietary $\mathrm{Mn}$ [125]) is rapidly absorbed through passive diffusion or active transport in the intestine, by a biphasic pattern with a saturable process similar to other divalent cations, most probably using SLC11A2 in enterocytes [124]. This may explain the observed interdependency of $\mathrm{Mn}$ with other metals 
decrease intestinal Mn assimilation [127]. At the cellular level, SLC11A2 not only participates to direct $\mathrm{Mn}$ entry into the cytosol, owing to its presence in the plasma membrane, but it is also implicated in $\mathrm{Mn} 2+$ transfer from early endosomes to cytosol consecutively to transferrin (TF) endocytosis by the TFR [128]. Indeed, while TF synthetized in the liver is very well known to bind and safely transport Fe3+ in blood plasma for delivery to cells expressing specific highaffinity transferrin receptors (TRF1-2), it may also transport other biometals, mainly Mn3+ but also $\mathrm{Cu} 2+$ and $\mathrm{Zn2}+[129]$. With regard to $\mathrm{Mn}$, the quantitative importance of metal transport into cells by the TFR pathway is controversial. Whereas Mn3+-Tf transport is markedly slower than other $\mathrm{Mn}$ transport mechanisms [130], it has been proposed that $\mathrm{Tf}$ is the major $\mathrm{Mn}$ carrying protein in the plasma $[129,131,132]$. After its passage from intestinal cells into the blood, and prior its binding to $\mathrm{TF}$, it is postulated that $\mathrm{Mn2}+$ oxidation is performed by ceruloplasmin or hephaestin $[56,133]$, two Cu-dependent ferroxidases.

Finally, SLC39A8 and SLC39A14, two ZIP family porters, appear as key Mn influx transporters. This family encompasses 14 paralogues in mammals classified into four subfamilies (ZIPI, ZIPII, gufA and LIV-1 (or LZT)), all involved in Zn influx transport, most probably through a metal:HCO3 symport mechanism [134, 135]. All these proteins are located at the plasma membrane, with the exceptions of SLC39A7 (ER and Golgi), SLC39A9 (Golgi), SLC39A11 (Golgi and nucleus) and SLC39A13 (Golgi). The importance of ZIP proteins in metal homeostasis, most especially $\mathrm{Zn}$, has been underlined in several pathologies, as reported in section 2.3. Interestingly, SLC39A8 and SLC39A14, both belonging to the LIV-1 subfamily, differ from the other ZIP family members by their broader selectivity: Mn, Zn, Fe and even Cd, highly toxic $[134,135]$. Their roles in $\mathrm{Mn}$ transport look essential, as they have been shown to regulate systemic Mn homeostasis. It was first proposed that SLC39A14, abundant in intestinal, pancreatic and hepatic tissues, imports $\mathrm{Mn}$ in liver and pancreas for further excretion in the bile [136], but a study using a liver-specific ZIP14 KO model did not validate this hypothesis [120]. Instead, a recent finding suggested that intestinal SLC39A14 could mediate enterocyte basolateral reuptake of freshly absorbed $\mathrm{Mn}$ [137]. Elsewhere, it has been shown that SLC39A14 promotes cellular assimilation of Fe from transferrin [138]. The role of SLC39A8 on systemic Mn homeostasis would be antagonistic to SLC39A14 since it mainly localizes to the hepatocyte canalicular membrane and in the proximal tubule of the kidney where it could reclaim Mn from the bile and urine, respectively $[14,139]$. With regard to SLC39A8, a special 
attention must be paid to the fact that its deficiency causes both a type II CDG and the Leighlike syndrome (necrotizing encephalopathy characterized by defects in mitochondrial energy production). In SLC39A8-CDG, the patients exhibit systemic Mn deficiency, and most particularly low serum Mn levels, probably through insufficient hepatic, renal and/or intestinal reabsorption [112]. The consequences of mutations in SLC39A8 are the hypogalactosylation of serum proteins, possibly via reduced activity of the Mn-dependent $\beta-1,4$ galactosyltransferase 1 [112] (Fig. 1), and increased oxidative stress in the Leigh syndrome, due to impaired activity of Mn-dependent mitochondrial superoxide dismutase (MnSOD) [140].

\subsection{Mn efflux proteins}

Although $\mathrm{Mn}$ plays an important role in the oxidative stress response of organisms, as mentioned in section 2.1.2, manganism and parkinsonism in Mn-exposed workers have proven its deleterious effects in cells and tissues, thus requiring efficient efflux systems. As shown in Table 1, $8 \mathrm{Mn}$ efflux transporters, whose principal roles are to get rid of $\mathrm{Mn}$ excess and other divalent metals from the cytosol, but also to provide organelles with metal for metalloproteins, have been characterized and/or hypothesized as $\mathrm{Mn}$ transporters. Among these porters, SLC30A10 (CDF family) [87] and SLC40A1 (Ferroportin - FPN family) [141] are primarily expressed at the plasma membrane. The other porters direct the flux of metals from the cytosol to mitochondria (Mitochondrial Calcium Uniporter (MCU) of the $\mathrm{Mg} / \mathrm{Ca}$ Uniporter (MCU) family [142] and SLC11A2 of the NRAMP family [108]) or to compartments of the secretory pathway : TMEM165 (CaCA2 family) [143] and ATP2C1 (P-ATPase family) [5] to the Golgi, possibly ATP13A1 [144] and ATP2A2 [145] to the ER, and possibly ATP13A4 to endosomes/lysosomes $[89,146]$. It is assumed that all these transporters may not only maintain cytosolic metal homeostasis (detoxification), but also ensure metal storage in the cell compartments and/or proper metal homeostasis of the corresponding compartments for specific processes such as glycosylation. It should be noted that for some of the abovementioned transporters, their exact ion specificity and function still need to be thoroughly established. In particular, the function in metal transport of members of the P5 ATPase subfamily, such as ATP13A1 and ATP13A4, is still under debate. Indeed, as mentioned above, it was recently demonstrated that ATP13A2 (PARK9), another member of the P5 ATPase 
623 subfamily formerly hypothesized as a metal transporter involved in Mn detoxification [89], is actually a polyamine transporter [90].

With regard to glycosylation, a special attention must obviously be paid to porters expressed in ER and Golgi where glycan assembly occurs. Of course, TMEM165, causing CDG, looks an essential molecular determinant in such process, and the following section will thus be dedicated to review our current knowledge on this porter. Beside TMEM165, ATP2C1 (SPCA1) has been described as another Mn Golgi porter [5]. Whereas ATP13A1 belongs to the P5Abelongs to the P2A-ATPase subgroup whose members are almost exclusively involved in $\mathrm{Ca}$ transport. However, it has been shown that SERCA pumps may transport both Ca and Mn into the ER, although $\mathrm{Mn}$ is only a weak competitor of $\mathrm{Ca}$ [145], while the SPCA pumps may serve as Golgi efflux pumps for both $\mathrm{Ca}$ and $\mathrm{Mn}$ [147]. High affinity has been reported for both metals, in both yeast (Pmc1 and Pmr1, in vacuole and Golgi, respectively) and humans (ATP2C1 and 2 in Golgi) $[147,148]$. Unlike the SERCAs which translocate two Ca per cycle, the SPCA pumps translocate only one cation per cycle (reviewed in [149]). It has to be noted that ATP2C1 is more selective for Mn transport than Pmr1, but that this later is also a Cd transporter [148]. Whereas the ATP2C1 pump is ubiquitously expressed in tissues, ATP2C2 has a more restricted tissue distribution (mostly in brain and testis) than ATP2C1 [150]. ATP2C1 is involved in responses to Golgi stress, apoptosis, midgestational death and the management of $\mathrm{Mn}$ induced neurotoxicity. Interestingly, as mentioned in section 2.3, loss of a functional copy of the ATP2C1 gene is associated with the Hailey-Hailey disease, an acantholytic skin disorder, thus underlining its importance in metal transport [99]. In keratinocytes of the Hailey-Hailey disease patients, decreased concentration of intracellular ATP leading to impaired actin reorganization was observed. This may be explained either by a decrease of ATP synthesis due to Ca overload in mitochondria and subsequent uncoupling of oxidative phosphorylation, or by an increased consumption of ATP due to increased activity of CaATPases [99]. On a structural point of view, it is worthy to note that mutations of key Asp residues in the EF hand motifs of ATP2C1 result in the alteration of both $\mathrm{Ca}$ and $\mathrm{Mn}$ transport activities. For example, D742Y mutation abrogates transport of both metals whereas a G309C mutation results in a selective loss of $\mathrm{Mn}$ transport [99]. ATP2C1 activity is dependent on $\mathrm{Mg}$ and its regulation is mediated by CFL1 (actin filament severing protein cofilin-1), required for 
recruitment of actin, and itself regulated by both calcineurin and the CaM kinase II [151]. Whereas it is still unclear if the Hailey-Hailey disease is connected to a defect in $\mathrm{Mn}$ homeostasis, it has been proposed that ATP2C1 is crucial in detoxifying cytosolic $\mathrm{Mn}$ accumulation by sequestering it into the secretory pathway $[5,100,101]$.

\subsection{TMEM165 : a newcomer in the Mn Golgi transport landscape}

Since the discovery of mutations in TMEM165-CDG patients, a decade or so ago [111], special attention has been paid to decipher structural and functional properties of the protein. Interestingly, it was recently demonstrated that the protein is essential for $\mathrm{Mn}$ efflux from cytosol to Golgi $[143,152]$.

\subsubsection{An ubiquitous member of the UPF0016 family} Human TMEM165, also called Transmembrane Protein TPARL or PT27, is a 324 aminoacid uncharacterized protein family 0016 (UPF0016 ; Pfam accession number, PF01169)) encompassing putative secondary ion transporters whose a common feature in the sequence is the presence of one or two signature EXGDK/R motifs ( $\mathrm{X}$ is any hydrophobic residue). As indicated in Table 1, TMEM165 is classified in the CaCA2 (Caz+:H+ Antiporter-2) family, although the recent results demonstrating that TMEM165 plays a leading role in Golgi Mn homeostasis, as reported below, possibly making this classification not appropriate. The proteins of the UPF0016 family are particularly well conserved from prokaryotes and eukaryotes, since itthey may be found in about one thousand and five hundred species of these two categories of living organisms, respectively [153]. The best characterized homologous proteins of TMEM165 are, in yeast : Gdt1p, a 280 aminoacid protein which mainly differs from TMEM165 by the absence of the first transmembrane domain and a 10 aminoacid-longer central cytosolic loop, in plants : PAM71 (Photosynthesis-affected mutant 71) [154], CMT1 (Chloroplast Manganese Transporter 1) [155] and their three homologs PML3, PML4 and PML5 [156] ; in prokaryotes : MneA of Vibrio cholerae [157] and Mnx (SynPAM71) of the cyanobacteria Synechocystis [158, 159].

In humans, according to the Human Protein Atlas, TMEM165 is virtually expressed in all tissues and cells with a strong expression in brain. Unlike PAM71 and CMT1 which are expressed in 
the thylakoid and chloroplast membranes of plant cells $[155,160]$, and Gdt1p which is present in the cis- and medial Golgi of yeast [154], TMEM165 mainly colocalizes in the medial-transextent in late endosomes/lysosomes and at the plasma membrane $[153,161]$. Interestingly, it was recently reported that plant PML3 also localizes to the Golgi, whereas PML4 and PML5 are found in the ER [156]. Elsewhere, splice transcript variants of TMEM165 with unknown functions were highlighted, more particularly two 129 and 259 aminoacid isoforms both localizing in the ER of all cells but brain cells for the shorter form, and in the temporal lobe of brain for the longer form [162].

\subsubsection{Phenotype and glycosylation defects in TMEM165-CDG patients}

Up to now, a dozen of patients presenting mutations in TMEM165 gene have been worldwide diagnosed, among which the five first cases reported in 2012, and a more recent case in 2016, have been extensively studied [111, 163]. As shown in Table 3, among those six patients, the most severely affected ones presented a particular phenotype with strong bone and cartilage dysplasia, in addition to growth abnormalities, muscular hypertrophy, excess fat production, increased serum transaminases and LDH, decreased coagulation factors, and cardiac defects in some instances. Such skeletal dysplasia phenotype was further observed in a TMEM165deficient zebrafish model [164]. At the cellular level, the fibroblasts of TMEM165-CDG patients exhibited significant dilatation of Golgi and fragmentation of trans-Golgi [111], some alterations that have been observed in cells of other CDG patients presenting deficiencies in COG proteins [165], involved in vesicular trafficking, but also in ATP6V1E1 or ATP6V1A [166] and TMEM199 [167] which take part in the V-ATPase complex involved in Golgi proton homeostasis. The affected individuals, identified as CDG-II patients, exhibited abnormal Nglycans partially lacking terminal sugars, especially galactose and sialic acid, but also fucose, as well as abnormal high-mannose type $\mathrm{N}$-glycans $[111,163,168,169]$. Such defects in $\mathrm{N}$ glycans were retrieved in TMEM165-depleted models such as the zebrafish model [164] and HEK293 cell model where an impairement of the transfer of Gal/GalNAc to glycolipids was also observed [152]. Impaired N-glycosylation was also found in gdt1 $\Delta$ null yeast mutants placed in conditions of high Ca concentration, in which an increased electrophoretic mobility of secreted invertase, an exclusively $\mathrm{N}$-glycosylated protein, was demonstrated [152, 170]. With regard to O-glycosylation, whereas only slight defects were detected in patients in the 
princeps study [111], as demonstrated by IEF assay of apoliprotein CIII, a decrease of the ST

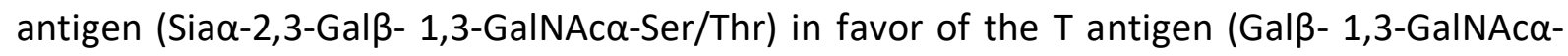
Ser/Thr) was reported [169]. Lastly, impact of TMEM165 deficiency on GAG synthesis was observed in the zebrafish model where chondroitin sulfate proteoglycan (aggrecan) expression was altered [164]. In this model, the abnormal cartilage development confirmed the skeletal dysplasia phenotype found in patients. Interestingly, N-glycans defects were rescued in TMEM165-CDG patients orally-supplemented with galactose [171].

\subsubsection{Role(s) in membrane transport}

The function(s) of TMEM165 is(are) still under debate but the latest data are strongly in line with a role of a membrane transporter regulating Golgi Ca and Mn homeostasis.

The first studies on TMEM165 and its yeast ortholog Gdt1p hypothesized a role in Ca homeostasis. In yeast, the first evidence came from Gdt1 $\Delta$ mutants presenting a strong growth defect phenotype in presence of high concentrations of $\mathrm{CaCl}_{2}$ (500-700mM) [153]. Then, the transport of $\mathrm{Ca}$ by Gdt1p was demonstrated by expressing the protein in Lactobacillus lactis and probing intracellular Ca changes with Fura-2 [172], and similar transport by TMEM165 was suggested from patch-clamp experiments using overexpression of the protein at the surface of HeLa cells [170]. In addition, while disturbance in Golgi proton homeostasis could not be initially evidenced in TMEM165-deficient patients' cells, a general decrease in the $\mathrm{pH}$ of acidic compartments was observed [153]. Furthermore, a very recent study using in situ fluorescent and photoacoustic imaging of Golgi pH has evidenced that the absence of TMEM165 causes Golgi acidification [173]. Taken as a whole, these studies suggest that both TMEM165 and Gdt1p would act as $\mathrm{Ca} / \mathrm{H}+$ antiporters. Interestingly, such activity for Gdt1p has been recently connected to the handling of $\mathrm{H}+$ produced in the Golgi as a byproduct of the glycosylation reactions using nucleotide sugars as donors [174]. The authors hypothesized that Gdt1p would retrieve $\mathrm{H}+$ from the Golgi while permitting the luminal entry of $\mathrm{Ca}$, whereas the yeast inorganic phosphate (Pi) transporter Erd1 (homolog of human XPR1) would retrieve Pi from the Golgi, another byproduct of the glycosylation reactions [174]. Since disturbances in $\mathrm{Ca}$ and proton Golgi homeostasis are known to impact the integrity, trafficking and functions of the organelle, it is conceivable that impaired glycosylation could result from defective TMEM165 or Gdt1p Ca/proton transporters. 
However, this sole $\mathrm{Ca} / \mathrm{H}+$ exchanger function can be reconsidered in the light of further results demonstrating strong links between TMEM165 and Mn homeostasis. In fact, a role of the protein in Mn transport is not surprising given that several other members of the UPF0016 family, mentioned in section 3.3.1, were also reported as Mn transporters : MneA ( $V$. cholerae) [157], PAM71 and CMT1 in plants [155, 160] and Mnx (SynPAM71) of Synechocystis $[158,159]$. A first clue was given by the observation that $\mathrm{Mn}$ supplementation restored a normal glycosylation both in Gdt1 $\Delta$ null mutant yeasts cultured in the presence of high Ca concentrations and in TMEM165-depleted cells [152]. Another major clue was provided by studying the degradation of two proteins in presence of increased intracellular $\mathrm{Mn}$ concentrations in human cells : GPP130 (Golgi phosphoprotein 4) and TMEM165 itself [152]. Indeed, GPP130, which is known to be a specific Golgi Mn sensor targeted to lysosomal degradation via a Rab-7-dependent mechanism mediated by sortilin [175], exhibited an altered Mn sensitivity in TMEM165 depleted cells. Similarly to GPP130, TMEM165 was highlighted as a novel Golgi protein sensitive to increased cytosolic Mn concentration. The molecular mechanism of its $\mathrm{Mn}$-induced lysosomal degradation differs from that observed for GPP130 and is currently not deciphered [176]. Lastly, transport of Mn by both the yeast protein Gdt1p and a truncated form of TMEM165 using their overexpression in L. lactis and quenching of Fura2-emitted fluorescence was recently evidenced [172, 177]. However, the authors showed that the affinity of Gdt1p for Mn was lower than that for Ca. They also showed that Gdt1p is not only involved in the resistance to high Mn concentration and the control of Mn stores, but also probably in the modulation of cytosolic Mn concentration [172]. All these results therefore strongly support the assertion that TMEM165 is involved in Golgi Mn homeostasis whose disruption would affect any of the Mn-dependent GTs involved in glycosylation (see section 2.1.2), of which the $\beta$-1,4-galactosyltransferase 1 could be the most impacted (Fig. 1). As illustrated in Figure 1, impaired systemic and cellular Mn homeostasis in SLC39A8-CDG patients could similarly lead to $\beta$-1,4-galactosyltransferase 1 dysfunction and defective N-glycosylation [112].

Finally, these data support the hypothesis that TMEM165 could be either all at once a proton, $\mathrm{Ca}$ and Mn transporter. Using a TMEM165-deficient mice model, it was indeed showed that TMEM165 is crucial for the biosynthesis of lactose in lactating mammary gland where both $\mathrm{Ca}$ and $\mathrm{Mn}$ milk concentrations are found significantly lower than in control mice [178]. As 
proposed as early as 2012 [111], such results tie well with the observation that TMEM165 expression in mice is high during lactation and markedly declines during mammary involution [179]. Lactose synthetase, which generates lactose from glucose and UDP-galactose, consists of $\mathrm{N}$-acetyllactosamine synthase, a Mn-dependent $\beta$-1,4-galactosyltransferase 1 and $\alpha$ lactalbumin, a Ca-binding protein promoting glucose binding to the transferase. The authors hypothesized that TMEM165 works as a transporter importing Mn and Ca into the Golgi of mammary gland cells to support the lactose synthetase activity in exchange for protons generated by lactose synthesis as byproducts [179].

In summary, many evidences are strongly in favour of a role of Golgi $\mathrm{Ca} / \mathrm{Mn}$ transporter for TMEM165, and confirm the crucial role of the protein in controlling Mn homeostasis required for Golgi glycosylation. However, to date, no definitive evidence permits to determine whether TMEM165 is an antiporter exchanging $\mathrm{Mn}$ for $\mathrm{Ca}$, or $\mathrm{Mn}$ and/or $\mathrm{Ca}$ for protons (or Pi) in a $\mathrm{Mn} / \mathrm{C}$ a dependent way.

\subsubsection{Structural motifs important for TMEM165 functions}

As mentioned in section 3.3.1, a common structural feature of the UPF0016 family proteins is the presence of two highly conserved EXGDK/R motifs. In human TMEM165, the two motifs are found in sequences ${ }^{108} \mathrm{ELGDK}^{112}$ of the second predicted transmembrane segment, facing hydrophobic regions and with an antiparallel orientation [143] (Fig. 3). In addition, two cytosolic loops of TMEM165 possess putative lysosomal targeting motifs : a tyrosine-based sorting motif $\mathrm{YXX} \varnothing,{ }^{124} \mathrm{YNRL}^{127}$, located in the first cytosolic loop and ${ }^{209} \mathrm{LL}^{210}$ present in a noncanonical $[D E] X X X L[L I]$ sequence of the second loop organized in a coiled coil domain [161] (Fig. 3). Such motifs are known to interact with adaptor proteins complexes AP1-4 able to recruit clathrin and to initiate the formation of coated vesicles. Interestingly, it has been shown that this second loop may possess a Ca-dependent regulatory function in Vcxp1, a yeast vacuolar $\mathrm{Ca} / \mathrm{H}+$ exchanger of the CaCA family [154].

Within the TMEM165 sequence, the characterization of mutations in patients together with in vitro experiments probing mutated recombinant DNA constructs shed light on the importance of peculiar aminoacid patterns in protein function and trafficking (Fig. 3). From six patients identified with TMEM165-CDG, four different mutations were detected (Table 3). 
Three patients possessed a $(c .792+182 \mathrm{G}>\mathrm{A})$ mutation causing the activation of a cryptic splice donor and the production of both full-size and truncated proteins [111]. It was shown that the truncated protein cannot not be expressed. Point mutations were evidenced in the three other patients : p.Arg126His, p.Arg126Cys + p.Gly304Arg, and p.Glu108Gly [111, 163]. Interestingly, these mutations have enlighten the functional importance of the two abovereported motifs in TMEM165 : the lysosomal targeting sequence ${ }^{124} \mathrm{YNRL}^{127}$ and the UFP0016 family signature motif ${ }^{108}$ ELGDK $^{112}$. Indeed, using expression of mutated GFP-tagged proteins in an in vitro cell model, it was demonstrated that mutations R126H and R126C led to preferential TMEM165 targeting to the lysosomal/endosomal compartments and also to the plasma membrane, whereas Y124 was found essential for TMEM165 Golgi exit [161]. Conversely, mutation in E108 does not affect the Golgi localization of TMEM165, leading to the hypothesis that it may alter its function. Studies on the yeast model indeed supported this hypothesis, since mutation of E53 in Gdt1p (corresponding to E108 in TMEM165) and mutations in the other acidic and polar aminoacids of both conserved EXGDK/R motifs proved these motifs to be essential for yeast Ca tolerance and response to salt stress, as well as for the glycosylation process [180]. However, mutation of R71 of Gdt1p (corresponding to R126 in TMEM165) did not affect growth, expression and activity of the protein, suggesting that this arginine is not essential in yeast [170]. The lysosomal targeting motif ${ }^{124} \mathrm{YNRL}^{127}$ of TMEM165 is actually not conserved in Gdt1p. Interestingly, the degradation of the TMEM165 variant with point mutation p.Glu108Gly observed in a CDG patient [163] was found to be less sensitive to $\mathrm{Mn}$, whereas such mutation did not abolish the protein function in Golgi glycosylation [176]. These results clearly evidence the importance of E108 of the cytosolic ${ }^{108} \mathrm{ELGDK}^{112}$ motif of TMEM165 in its Mn-induced degradation, but also question its direct participation to $\mathrm{Mn}$ transport into the Golgi. In contrast, the variant $\mathrm{R} 126 \mathrm{H}$ was sensitive upon $\mathrm{Mn}$ exposure [176]. Finally, a very recent study using 10 different mutations within the two conserved EXGDK/R motifs of TMEM165 has clarified their contribution in the function of the protein in Golgi glycosylation and in its Mn sensitivity [181]. Indeed, the results demonstrate that E248 (second motif) is crucial for Golgi glycosylation, while E108 (first motif) is not. In addition, paying attention to the couple of aminoacids next to the motifs : ${ }^{112} \mathrm{KT}^{113}$ and ${ }^{252} \mathrm{RS}^{253}$, this work evidenced that only the polar aminoacids T113 and S253 are also crucial for glycosylation, thus raising the hypothesis that they may undergo post-translational modifications playing a control in the functionality of TMEM165. Taken as a whole, those 
results suggest that both conserved motifs constitute the cation binding sites of TMEM165 and participate to metal transport. Furthermore, they showed that three aminoacids of the first motif are crucial for TMEM165 Mn sensitivity: E108, D111 and T113 [181].

All $18 \mathrm{Mn}$ transporters mentioned in the previous paragraphs have been reported in the scheme of Figure 2 illustrating Mn transport through the cell compartments. Many pieces of the puzzle have obviously yet to be put in place to get a clear picture of the mechanisms governing $\mathrm{Mn}$ homeostasis. This challenge is made even more difficult that virtually all transporters transport two or more metals, especially $\mathrm{Ca}$, making $\mathrm{Mn}$ homeostasis intimately linked to other metal homeostasis. Unfortunately, in comparison to other divalent biometals, most especially $\mathrm{Fe}, \mathrm{Ca}, \mathrm{Mg}, \mathrm{Cu}$ and $\mathrm{Zn}$, whose mechanisms of homeostasis regulation in cells are well documented, little is known with regard to $\mathrm{Mn}$, and even less with regard to Golgi homeostasis where the presence of this metal is an absolute requirement for glycosylation. As illustrated in Figure 2, five proteins, whose Mn transport activity in the secretory pathway (ER and Golgi) has been reported or hypothesized, are ubiquitously present in human cells : ATP2C1, ATP2A2 and APT13A1 (primary porters), TMEM165 and presumably SLC11A2 (secondary porters). Interestingly, with the exception of ATP13A1, an orthologue of yeast Mn transporter Spf1p [144] described as a putative Mn efflux transporter from cytosol to ER [86], and SLC11A2, a protein with a broad divalent metal specificity primarily located in the plasma membrane and endosomes [108], all proteins were reported as carriers for both $\mathrm{Mn}$ and Ca. Hence, it may be expected that, while both $\mathrm{Ca}$ and $\mathrm{Mn}$ homeostasis are intimately connected, those porters play distinct functions in maintaining those homeostasis.

With regard to Mn homeostasis, the latest results suggest that TMEM165, whose defects are detected in CDG patients, is a main contributor to Mn homeostasis in the Golgi compartments where terminal glycosylation is achieved, most especially in trans-Golgi [143]. This also suggests that the P-ATPases ATP2A2, and ATP2C1, whose key functions in the transfer of $\mathrm{Ca}$ from the cytosol to the secretion pathway have been clearly evidenced [149], would be better implicated in maintaining cytosolic $\mathrm{Mn}$ homeostasis through detoxification mechanisms in $\mathrm{Mn}$ excess conditions, than actively contributing to Golgi $\mathrm{Mn}$ homeostasis suitable to the functions of glycosylation enzymes. This hypothesis is supported by the observation that, unlike 

defects $[97,98]$. However, in vitro evidences that ATP2C1 and TMEM165 have high affinities for both $\mathrm{Ca}$ and $\mathrm{Mn}$, and even better affinity for $\mathrm{Mn}$ than $\mathrm{Ca}$ in the case of ATP2C1, and better affinity for Ca than Mn for TMEM165 [177, 182], are obviously not supportive of this hypothesis. However, it cannot be excluded that, in a cellular context, the metal transport specificity and kinetics of both transporters may be influenced and modulated by microenvironmental parameters at the Golgi membrane, such as casual partner proteins (e.g. the actin filament severing protein cofilin-1 interacting with ATP2C1 [151]) or lipids, local concentrations of metals and possible post-translational modifications of the transporters. This latter possibility is supported by the recent evidence that T113 and S253 of TMEM165 are crucial for glycosylation [181]. Both amino acid residues, which constitute potential targets for post-translational modifications, are indeed contiguous with the EXGDK/R motifs of the protein (Fig. 3) and could thus play a role in modulating its functionality. At last, a mutual regulation of the ion specificity of ATP2C and TMEM165 cannot be excluded.

Little is known about the mechanisms controlling Golgi Mn homeostasis but recent works deciphering the regulation of TMEM165 expression, together with its possible links with the other Golgi porters, draw a clearest picture (Fig. 4). Usually, regulation of transporter expression is achieved by a great variety of different ways including regulation of gene expression, mainly transcriptional and post-translational (e.g. phosphorylation, degradation and intracellular relocalization), but also allosteric inhibition or activation, and sensitivity to ion concentration (not necessarily the ions they preferentially transport). Another layer of complexity is provided by the simultaneous expression in cells of high and low affinity membrane transporters, usually transporting a broad range of metals, that allow the maintenance of metal homeostasis in conditions of either metal limitation or excess [183]. In the case of TMEM165, unlike its plant homolog in chloroplasts, CMT1 [155], no transcriptional down-regulation in $\mathrm{Mn}$-surplus conditions was observed. Instead, it has been demonstrated that down-regulation is achieved by degradation of the protein. Indeed, when cells undergo high Mn extracellular concentrations, TMEM165, like Gdt1p in yeast, is targeted to lysosomes for degradation [176]. Interestingly, such mode of regulation by excess $\mathrm{Mn}$ was also recently reported for SLC39A14 found localized at the surface of hepatocytes [184]. This regulation is similar to that of the Golgi GPP130 protein but, unlike this protein whose degradation is 
dependent on the Mn concentration in the Golgi lumen, TMEM165 or Gdt1p degradation has been shown to depend on cytosolic Mn concentration [176].

Furthermore, a functional link has been shown very recently in human cells between TMEM165 and ATP2C1, together with a close proximity of both proteins in the Golgi [185]. TMEM165 was indeed found almost absent from the Golgi of ATP2C1-deficient cells (Hap1 cells), as a consequence of lysosomal degradation. Furthermore, it was demonstrated that this degradation is directly related to the $\mathrm{Mn}$ transporter function of ATP2C1, from cytosol to the Golgi lumen. Those results are strongly in line with a previous work investigating the function of Gdt1p in yeast Golgi glycosylation, and supporting the hypothesis that Gdt1p imports Mn into the Golgi when Pmr1p, the homolog of ATP2C1 in yeast, exclusively transports Ca [186]. Importantly, they confirm the hypothesis that_cytosolic Mn concentration (potentially higher in ATP2C1-deficient cells than in normal cells) down-regulates the expression of TMEM165 in the Golgi. Elsewhere, although both affinity and transport rate of ATP2A2 are much lower for $\mathrm{Mn}$ than $\mathrm{Ca}$ [145], this latest work also indicates the significant role of ATP2A2 in the efflux of $\mathrm{Mn}$ from the cytosol into the secretory pathway. Indeed, overexpression of ATP2A2 in ATP2C1-deficient Hap1 cells allowed to rescue the presence of TMEM165 in the Golgi [185]. Another recent work suggesting the involvement of thapsigargin and cyclopiazonic acidsensitive pumps in the rescue of TMEM165-associated glycosylation defects by $\mathrm{Mn}$ in cells still expressing ATP2C1 is in support to this assertion [187]. The observation that ATP2C1 deficiency, unlike TMEM165, has no impact on glycosylation of LAMP2 and TGN46 [185] suggests that ATP2C1 is not essential in providing Mn to the glycosylation machinery in the Golgi. Actually, as hypothesized in previous reports $[5,100$, 101], its main role would be to detoxify the cytosol from Mn excess, like the other Mn efflux transporters at the plasma membrane (proteins of the P-ATPase, CDF and FPN families shown in Fig. 2) [86], by transporting the metal to the Golgi. It is of note that this may be contradictory to the results obtained for Pmr1p. In yeast, a defect of Pmr1p indeed affects all at once the terminal chains of glycans, the proteolysis process, and the traffic of proteins in the secretory pathway [188]. However, there is evidence that, not only no protein homologous to ATP2A2 is expressed in the ER of yeast, but Pmr1p, expressed in the medial Golgi, is also the major transporter contributing to $\mathrm{Mn}$ transport into the secretory pathway. It was indeed 
demonstrated that a deficiency of Pmr1p in yeast has a great impact on glycosylation in the secretory pathway [152].

One might wonder why TMEM165 Golgi expression in Golgi is down-regulated by high Mn cytosolic concentration. A possible explanation would be that, if an excess of cytosolic $\mathrm{Mn}$ drives ATP2C1 to rather function as a Mn cytosolic detoxifyer than a Ca transporter in Golgi, not only TMEM165 would be dispensable for providing Mn to Golgi Mn-metalloenzymes, but it could also contribute to excessive accumulation of $\mathrm{Mn}$ in Golgi. Furthermore, since TMEM165 is a probable Mn and/or Ca antiporter using a Golgi luminal ion gradient (with Ca, proton or inorganic phosphate as counterions), it cannot be excluded that its degradation could be required to either prevent a collapse of Golgi ion gradients, or/and to prevent it to work in reverse, hence counteracting ATP2C1 Mn-detoxifying action [185].

Finally, it cannot be excluded that mechanisms involving other transporters than TMEM165 and the ATP2A and ATP2C pumps regulate Mn homeostasis in cytosol and the secretory pathway lumen. For example, SLC11A2, a protein primarily expressed at the plasma that the cellular dynamics of SLC11A2 are regulated by the retromer complex which directs the protein to the cellular membrane via the trans-Golgi network by a retrorecycling process [190]. Hence, SLC11A2, considered as a major importer of $\mathrm{Mn}$ at the plasma membrane, in addition to Fe2+ and other divalent metals, could also play a significant role in Golgi Mn homeostasis. In support to this hypothesis, a recent study has demonstrated that, in plants, NRAMP2 is localized to the trans-Golgi network from which it could build-up a cytosolic Mn pool used to feed target compartments such as mitochondria, chloroplasts and vacuoles [191]. Similarly, it has been shown that, thanks to SLC11A2, the Golgi of human cells acts as a hub organelle in the delivery system for intracellular labile Fe2+ [192]. With regard to ATP13A1, the human homolog of yeast Mn ER transporter Spf1p [155], its function still needs to be definedcharacterized. Indeed, ATP13A1 is an ubiquitously expressed ER protein whose Mn transport activity was formerly hypothesized [86] but still questioned. Finally, other Golgi metal transporters, such as SLC10A7, a putative Ca transporter whose impairment in CDG patients results in a skeletal dysplasia phenotype comparable to that of TMEM165-CDG patients [193], could also be a player in Golgi ion homeostasis.

\section{Conclusion}



glycosylation machinery, in addition of a number of metalloproteins participating in vital physiological processes at both systemic and cellular levels. They greatly differ in humans by their abundance, the extent of their roles, either functional or structural, or both, and their chemical properties and casual toxicities. These differences require efficient transport and storage devices, sometimes shared by several metal species, allowing to reach the metalloproteins needing them as cofactors, at both the right place and the right concentration in cells. This review reports that any disturbance in metal homeostasis, often due to defective membrane transporters, is associated with severe pathologies including CDGs.

$\mathrm{Mn}$ is undoubtedly the most essential biometal for glycosylation. Such statement is based not only on the many previous studies reporting the requirement of $\mathrm{Mn}$ in the active sites of most GTs, but also on the recent characterization of CDG patients with gene defects in the membrane metal transporter SLC39A8 (ZIP8), allowing Mn uptake into cells and organisms, and TMEM165 delivering cytosolic Mn into the Golgi lumen. It turned out that TMEM165-CDG shed light on an unexpected newcomer in the array of known Mn transporters, most especially in Golgi where the SPCA proteins seemed hitherto to be the sole Mn transporters. Much remains to be done to decipher all aspects of TMEM165 functions but, based on the most recent results, an hypothetical scheme may reasonably be proposed. According to this scheme, while SPCA proteins would control cytosolic Mn homeostasis by directing any $\mathrm{Mn}$ excess from cytosol to the secretory pathway, TMEM165 would contribute, in normal conditions, to sustain a Golgi Mn homeostasis required for a correct functioning of GTs. Of course, the obtained data on biochemical properties of both transporters add complexity on the functioning scheme of these two proteins. It could well be that all hypotheses are wrong and more work is clearly needed in this area to disentangle the truth of the forgery. Furthermore, this hypothetical scheme in which SPCA proteins and TMEM165 might play different but complementary functions is consistent with the finding that excess cytosolic $\mathrm{Mn}$ leads to lysosomal degradation of TMEM165, which would otherwise antagonize the detoxifying action of SPCA proteins and/or perturbate Golgi $\mathrm{Ca} / \mathrm{Mn} / \mathrm{H}+$ homeostasis. Of course, an extralayer of complexity is given by the evidence that the primary function of SPCA proteins, like most other $\mathrm{Mn}$ transporters of the secretion pathway, is to transport $\mathrm{Ca}$, making $\mathrm{Mn}$ and $\mathrm{Ca}$ homeostasis intimately linked in Golgi. Furthermore, the observation that all influx 
991 and efflux transporters at the plasma membrane are involved in the transport of up to 7 992 different metals, including $\mathrm{Ca}, \mathrm{Mg}, \mathrm{Mn}, \mathrm{Fe}, \mathrm{Zn}, \mathrm{Cu}$ and $\mathrm{Ni}$, makes the equation even more 993 complex. Once gained a clearer picture of the whole set of Mn transporters, the next challenge 994 will undoubtedly be to understand the regulatory network of all biometals in Mn homeostasis.

995

996

997

998

999

.000

.001

.002

\section{Funding}

This work was supported by grants from the Agence Nationale de la Recherche (SOLVCDG project to FF), EUROGLYCAN-omics that was supported by ANR, under the frame of E-RARE-3, the ERA-Net for Research on Rare Diseases and within the scope of the International Associated Laboratory "Laboratory for the Research on Congenital Disorders of Glycosylation - from cellular mechanisms to cure - GLYCOLAB4CDG". 


\section{Legends to Tables and Figures}

.005

.006

Table 1 : List of ion channels and porters more specifically involved in the transport of $\mathrm{Ca}$,

$\mathrm{Mg}, \mathrm{Mn}, \mathrm{Zn}$ and/or Co in human cells. The channels and porters are grouped according their .008 family defined in the Transporter Classification Database (TCDB) approved by the International Union of Biochemistry and Molecular Biology (IUBMB) (http://tcdb.org/). Transported metals other than $\mathrm{Ca}, \mathrm{Mg}, \mathrm{Mn}, \mathrm{Zn}$ and $\mathrm{Co}$ are indicated ( $\mathrm{n}$. sel. : non selective channels). The main and secondary membrane localizations of transporters (PM: plasma membrane ; Golgi : Golgi membrane ; Endos.: endosomal and/or lysosomal membranes ; Mito. : mitochondrial membranes) are reported together with the direction of transport (Influx (I) : metal flux from the extracellular space or organelles to the cytosol; Efflux (E) : metal flux from the cytosol to the extracellular space or organelles). The list only includes the channels and porters whose mRNA have been detected in more than $95 \%$ of the organs, according to the RNA expression consensus dataset of the Human Protein Atlas (https://www.proteinatlas.org).

Table 2 : Main pathologies caused by or resulting in deficient homeostasis of $\mathbf{C a}, \mathbf{M g}, \mathbf{M n}$ and $\mathrm{Zn}$

.022

Table 3 : Mutations and main clinical phenotypes of TMEM165-CDG patients

.024

.025

Figure 1 : Impact of the $\mathrm{Mn}$ and proton transporters defective in CDG patients on the maturation steps of a complex biantennary fucosylated $\mathrm{N}$-glycan. The scheme shows the main steps of glycan processing and maturation in both ER and Golgi following the transfer of the $\mathrm{Glc}_{3} \mathrm{Man}_{9} \mathrm{GlcNAc}_{2}$ precursor to a newly-synthesized protein. The enzymes catalyzing the different steps of the N-glycosylation pathway are indicated: Gluc I \& II, glucosidases I and II ; ER Man I , ER mannosidase I ; $\alpha$-Man IA IB IC, $\alpha$-mannosidases IA, IB and IC ; MGAT1, Nacetylglucosaminyltransferase I ; $\alpha$-Man II, $\alpha$-mannosidase II ; MGAT2, Nacetylglucosaminyltransferase II ; FUT8, $\alpha-1,6$ fucosyltransferase ; B4GALT1, $\beta-1,4$ galactosyltransferase $1 ;$ ST6GAL1, $\alpha-2,6$ sialyltransferase 1 . The scheme illustrates the roles 
of SLC39A8 and TMEM165 in the transport of Mn through the plasma and medial/trans-Golgi membranes, respectively, and the role of the V-ATPase complex in transporting protons into the trans-Golgi. The color gradient (from pink to blue) aims to illustrate the $\mathrm{pH}$ gradient along the secretion pathway (ranging from about 7.2 in the ER to about 6.0 in the trans-Golgi). In CDG patients where those transporters are impaired, either $\mathrm{Mn}$ or $\mathrm{pH}$ homeostasis are disturbed, leading to incorrect glycan maturation in the last two steps of the glycosylation process : galactosylation and sialylation. Indeed, whereas defects in SLC39A8 or TMEM165 would deprive B4GALT1 of its metal cofactor, defects in subunits of the V-ATPase complex would impair enzymatic and/or sorting processes of both B4GALT1 and ST6GAL1 in the transGolgi compartment.

.044

Figure 2 : Scheme summarizing the $\mathrm{Mn}$ transporters found in most of the human cells. The .046 figure reports the ion channels and porters known to participate in the exchange of $\mathrm{Mn}$ between the cell compartments, from the list of Table 1 . The transporters are grouped according to their family, whose name is indicated in bold letters followed by (C) for channels and $(\mathrm{P})$ for porters). The arrows show the direction of ion fluxes generated by the transporters through the membranes in physiological conditions (green for influx to cytosol; yellow for efflux from cytosol). An asterisk precedes the channels/porters whose location is secondary in the membrane of a given cell compartment. The known metals transported by the channels

Figure 3 : Structural motifs required for TMEM165 functions. The structural motifs are .056 positioned on a schematic topology model of TMEM165 with seven transmembrane domains (TMD), predicted using the TMHMM v2.0 server tool (www.cbs.dtu.dk/services/TMHMM/). are indicated between brackets (n. sel. : non selective channels). The figure shows the amino acid sequences (CPK coloring) belonging either to the EXGDK/R motifs conserved in the UFP0016 protein family (red rounded squares) or to putative lysosomal targeting motifs (blue rounded squares). The potential roles of those amino acids in $\mathrm{Mn}$ transport and sensitivity, glycosylation and protein trafficking are commented in section 3.3.2. The purple stars indicate the positions of protein mutations found in the six TMEM165CDG patients reported in Table 3. 
Figure 4: Known and putative Mn transport systems between cytosol and the secretory pathway compartments. The figure illustrates the known and putative $\mathrm{Mn}$ transporters expressed in the secretory pathway (oval shapes with arrows indicating the direction of $\mathrm{Mn}$ and $\mathrm{Ca}$ (where appropriate) fluxes), and the effects of high cytosolic Mn concentrations on the lysosomal degradation of TMEM165 and the Mn transport activity of ATP2C1(2)) (black arrows with crosses in red circles). The colors of arrows are indicative of the metal transported (green for $\mathrm{Mn}$ and brown for $\mathrm{Ca}$ ), while their thickness are meant to be proportional to the importance of $\mathrm{Mn} / \mathrm{Ca}$ fluxes. The background and brim colors of oval shapes indicate the main and secondary metal transport functions of the transporters, respectively (green for $\mathrm{Mn}$, brown for Ca and grey for other divalent metals). Question marks indicate putative metal fluxes. The filled triangles in the background symbolize the direction of putative $\mathrm{Mn}$ (light green) and $\mathrm{Ca}$ (light yellow) concentration gradients along the secretory pathway compartments.

.078 


\section{REFERENCES}

[1] K.J. Waldron, J.C. Rutherford, D. Ford, N.J. Robinson, Metalloproteins and metal sensing, Nature, 460 (2009) 823-830.

[2] Lyons, T.J., Eide, D.J., Transport and storage of metal ions in biology, 2007.

[3] K.D. Cashman, Calcium intake, calcium bioavailability and bone health, Br. J. Nutr., 87 Suppl 2 (2002) S169-177.

[4] J. Elíes, M. Yáñez, T.M.C. Pereira, J. Gil-Longo, D.A. MacDougall, M. Campos-Toimil, An Update to Calcium Binding Proteins, Adv. Exp. Med. Biol., 1131 (2020) 183-213.

[5] K. Van Baelen, L. Dode, J. Vanoevelen, G. Callewaert, H. De Smedt, L. Missiaen, J.B. Parys, L. Raeymaekers, F. Wuytack, The Ca2+/Mn2+ pumps in the Golgi apparatus, Biochim. Biophys. Acta, 1742 (2004) 103-112.

[6] G. Davies, B. Henrissat, Structures and mechanisms of glycosyl hydrolases, Struct. Lond. Engl. 1993, 3 (1995) 853-859.

[7] C.S. Bond, P.R. Clements, S.J. Ashby, C.A. Collyer, S.J. Harrop, J.J. Hopwood, J.M. Guss, Structure of a human lysosomal sulfatase, Struct. Lond. Engl. 1993, 5 (1997) 277-289.

[8] S.-M. Glasdam, S. Glasdam, G.H. Peters, The Importance of Magnesium in the Human Body: A Systematic Literature Review, Adv. Clin. Chem., 73 (2016) 169-193.

[9] A.M.P. Romani, Intracellular magnesium homeostasis, in: R. Vink, M. Nechifor (Eds.), Magnes. Cent. Nerv. Syst., University of Adelaide Press, Adelaide (AU), 2011.

[10] A. Stangherlin, J.S. O'Neill, Signal Transduction: Magnesium Manifests as a Second Messenger, Curr. Biol. CB, 28 (2018) R1403-R1405.

[11] K. Tuschl, P.B. Mills, P.T. Clayton, Manganese and the brain, Int. Rev. Neurobiol., 110 (2013) 277-312.

[12] J.W. Whittaker, Manganese superoxide dismutase, Met. Ions Biol. Syst., 37 (2000) 587-611.

[13] K. Barnese, E.B. Gralla, D.E. Cabelli, J.S. Valentine, Manganous phosphate acts as a superoxide dismutase, J. Am. Chem. Soc., 130 (2008) 4604-4606.

[14] K.J. Horning, S.W. Caito, K.G. Tipps, A.B. Bowman, M. Aschner, Manganese Is Essential for Neuronal Health, Annu. Rev. Nutr., 35 (2015) 71-108.

[15] J.R. Rohde, R. Bastidas, R. Puria, M.E. Cardenas, Nutritional control via Tor signaling in Saccharomyces cerevisiae, Curr. Opin. Microbiol., 11 (2008) 153-160. 
[16] G.F. Carl, L.K. Blackwell, F.C. Barnett, L.A. Thompson, C.J. Rissinger, K.L. Olin, J.W. Critchfield, C.L. Keen, B.B. Gallagher, Manganese and epilepsy: brain glutamine synthetase and liver arginase activities in genetically epilepsy prone and chronically seizured rats, Epilepsia, 34 (1993) 441-446. of bradykinin, nitric oxide, and angiotensin II type 2 receptor in imidapril-induced angiogenesis, Hypertens. Dallas Tex 1979, 51 (2008) 252-258.

[18] N. Chebassier, O. El Houssein, I. Viegas, B. Dréno, In vitro induction of matrix metalloproteinase-2 and matrix metalloproteinase-9 expression in keratinocytes by boron and manganese, Exp. Dermatol., 13 (2004) 484-490.

[19] J.S. Nyman, C.C. Lynch, D.S. Perrien, S. Thiolloy, E.C. O'Quinn, C.A. Patil, X. Bi, G.M. Pharr, A. Mahadevan-Jansen, G.R. Mundy, Differential effects between the loss of MMP-2 and MMP-9 on structural and tissue-level properties of bone, J. Bone Miner. Res. Off. J. Am. Soc. Bone Miner. Res., 26 (2011) 1252-1260.

[20] H.O. Ishikawa, A. Xu, E. Ogura, G. Manning, K.D. Irvine, The Raine syndrome protein FAM20C is a Golgi kinase that phosphorylates bio-mineralization proteins, PloS One, 7 (2012) e42988.

[21] T.T. Paull, R.A. Deshpande, The Mre11/Rad50/Nbs1 complex: recent insights into catalytic activities and ATP-driven conformational changes, Exp. Cell Res., 329 (2014) 139-147.

[22] L.L. Lairson, B. Henrissat, G.J. Davies, S.G. Withers, Glycosyltransferases: structures, functions, and mechanisms, Annu. Rev. Biochem., 77 (2008) 521-555.

[23] B. Ramakrishnan, E. Boeggeman, V. Ramasamy, P.K. Qasba, Structure and catalytic cycle of beta-1,4-galactosyltransferase, Curr. Opin. Struct. Biol., 14 (2004) 593-600.

[24] H.H. Wandall, H. Hassan, E. Mirgorodskaya, A.K. Kristensen, P. Roepstorff, E.P. Bennett, P.A. Nielsen, M.A. Hollingsworth, J. Burchell, J. Taylor-Papadimitriou, H. Clausen, Substrate specificities of three members of the human UDP-N-acetyl-alpha-D-galactosamine:Polypeptide $\mathrm{N}$ acetylgalactosaminyltransferase family, GalNAc-T1, -T2, and -T3, J. Biol. Chem., 272 (1997) 2350323514.

[25] T. Willer, K.-I. Inamori, D. Venzke, C. Harvey, G. Morgensen, Y. Hara, D. Beltrán Valero de Bernabé, L. Yu, K.M. Wright, K.P. Campbell, The glucuronyltransferase B4GAT1 is required for initiation of LARGE-mediated $\alpha$-dystroglycan functional glycosylation, ELife, 3 (2014).

[26] K. Inamori, T. Willer, Y. Hara, D. Venzke, M.E. Anderson, N.F. Clarke, P. Guicheney, C.G. Bönnemann, S.A. Moore, K.P. Campbell, Endogenous glucuronyltransferase activity of LARGE or LARGE2 required for functional modification of $\alpha$-dystroglycan in cells and tissues, J. Biol. Chem., 289 

D-xylose: alpha-D-xyloside alpha 1-->3xylosyltransferase activity in human hepatoma cell line HepG2, J. Biochem. (Tokyo), 120 (1996) 1002-1006.

[28] A.S. Palma, V.A. Morais, A.V. Coelho, J. Costa, Effect of the manganese ion on human alpha3/4 fucosyltransferase III activity, Biometals Int. J. Role Met. Ions Biol. Biochem. Med., 17 (2004) 35-43.

[29] A. Takeya, O. Hosomi, T. Kogure, Identification and characterization of UDP-GaINAc: NeuAc alpha 2-3Gal beta 1-4GIc(NAc) beta 1-4(GalNAc to Gal)N-acetylgalactosaminyltransferase in human blood plasma, J. Biochem. (Tokyo), 101 (1987) 251-259.

[30] M. Persson, J.A. Letts, B. Hosseini-Maaf, S.N. Borisova, M.M. Palcic, S.V. Evans, M.L. Olsson, Structural effects of naturally occurring human blood group B galactosyltransferase mutations adjacent to the DXD motif, J. Biol. Chem., 282 (2007) 9564-9570.

[31] S. Müller, M. Schöttler, S. Schön, C. Prante, T. Brinkmann, J. Kuhn, C. Götting, K. Kleesiek, Human xylosyltransferase I: functional and biochemical characterization of cysteine residues required for enzymic activity, Biochem. J., 386 (2005) 227-236.

[32] T. Yada, M. Gotoh, T. Sato, M. Shionyu, M. Go, H. Kaseyama, H. Iwasaki, N. Kikuchi, Y.-D. Kwon, A. Togayachi, T. Kudo, H. Watanabe, H. Narimatsu, K. Kimata, Chondroitin sulfate synthase-2 Molecular cloning and characterization of a novel human glycosyltransferase homologous to chondroitin sulfate glucuronyltransferase, which has dual enzymatic activities, J. Biol. Chem., 278 (2003) 30235-30247. Kudo, H. Watanabe, H. Narimatsu, K. Kimata, Chondroitin sulfate synthase-3 Molecular cloning and characterization, J. Biol. Chem., 278 (2003) 39711-39725.

[34] Y. Tsutsui, B. Ramakrishnan, P.K. Qasba, Crystal structures of $\beta-1,4$-galactosyltransferase 7 enzyme reveal conformational changes and substrate binding, J. Biol. Chem., 288 (2013) 31963-31970.

[35] T. Okajima, Y. Nakamura, M. Uchikawa, D.B. Haslam, S.I. Numata, K. Furukawa, T. Urano, K. Furukawa, Expression cloning of human globoside synthase cDNAs Identification of beta 3Gal-T3 as UDP-N-acetylgalactosamine:globotriaosylceramide beta 1,3-N-acetylgalactosaminyltransferase, J. Biol. Chem., 275 (2000) 40498-40503.

[36] T. de Vries, J. Storm, F. Rotteveel, G. Verdonk, M. van Duin, D.H. van den Eijnden, D.H. Joziasse, H. Bunschoten, Production of soluble human alpha3-fucosyltransferase (FucT VII) by membrane targeting and in vivo proteolysis, Glycobiology, 11 (2001) 711-717. 
[37] H. Sprong, S. Degroote, T. Nilsson, M. Kawakita, N. Ishida, P. van der Sluijs, G. van Meer, 174 Association of the Golgi UDP-galactose transporter with UDP-galactose:ceramide galactosyltransferase allows UDP-galactose import in the endoplasmic reticulum, Mol. Biol. Cell, 14 (2003) 3482-3493.

[38] W. Chen, U.M. Unligil, J.M. Rini, P. Stanley, Independent Lec1A CHO glycosylation mutants arise from point mutations in $\mathrm{N}$-acetylglucosaminyltransferase I that reduce affinity for both substrates Molecular consequences based on the crystal structure of GIcNAc-TI, Biochemistry, 40 (2001) 87658772.

[39] S.M. Arnold, L.I. Fessler, J.H. Fessler, R.J. Kaufman, Two homologues encoding human UDPglucose:glycoprotein glucosyltransferase differ in mRNA expression and enzymatic activity, Biochemistry, 39 (2000) 2149-2163.

[40] K. Inamori, T. Willer, Y. Hara, D. Venzke, M.E. Anderson, N.F. Clarke, P. Guicheney, C.G. Bönnemann, S.A. Moore, K.P. Campbell, Endogenous glucuronyltransferase activity of LARGE or LARGE2 required for functional modification of $\alpha$-dystroglycan in cells and tissues, J. Biol. Chem., 289 (2014) 28138-28148.

[41] S. Jitrapakdee, A. Vidal-Puig, J.C. Wallace, Anaplerotic roles of pyruvate carboxylase in mammalian tissues, Cell. Mol. Life Sci. CMLS, 63 (2006) 843-854.

[42] Y. Kai, H. Matsumura, K. Izui, Phosphoenolpyruvate carboxylase: three-dimensional structure and molecular mechanisms, Arch. Biochem. Biophys., 414 (2003) 170-179.

[43] D.L. Purich, H.J. Fromm, F.B. Rudolph, The hexokinases: kinetic, physical, and regulatory properties, Adv. Enzymol. Relat. Areas Mol. Biol., 39 (1973) 249-326.

[44] L.A. Fothergill-Gilmore, H.C. Watson, The phosphoglycerate mutases, Adv. Enzymol. Relat. Areas Mol. Biol., 62 (1989) 227-313.

[45] D.P. Dowling, L. Di Costanzo, H.A. Gennadios, D.W. Christianson, Evolution of the arginase fold and functional diversity, Cell. Mol. Life Sci. CMLS, 65 (2008) 2039-2055.

[46] S. Yamasaki, K. Sakata-Sogawa, A. Hasegawa, T. Suzuki, K. Kabu, E. Sato, T. Kurosaki, S. Yamashita, M. Tokunaga, K. Nishida, T. Hirano, Zinc is a novel intracellular second messenger, J. Cell Biol., 177 (2007) 637-645.

[47] N. Roohani, R. Hurrell, R. Kelishadi, R. Schulin, Zinc and its importance for human health: An integrative review, J. Res. Med. Sci. Off. J. Isfahan Univ. Med. Sci., 18 (2013) 144-157.

[48] L. Leyssens, B. Vinck, C. Van Der Straeten, F. Wuyts, L. Maes, Cobalt toxicity in humans-A review 
of the potential sources and systemic health effects, Toxicology, 387 (2017) 43-56.

[49] P.F. Daniel, B. Winchester, C.D. Warren, Mammalian alpha-mannosidases--multiple forms but a common purpose?, Glycobiology, 4 (1994) 551-566.

[50] M. Bangera, G. Gowda K, S.R. Sagurthi, M.R.N. Murthy, Structural and functional insights into phosphomannose isomerase: the role of zinc and catalytic residues, Acta Crystallogr. Sect. Struct. Biol., 75 (2019) 475-487.

[51] T. Suzuki, I. Hara, M. Nakano, M. Shigeta, T. Nakagawa, A. Kondo, Y. Funakoshi, N. Taniguchi, Man2C1, an alpha-mannosidase, is involved in the trimming of free oligosaccharides in the cytosol, Biochem. J., 400 (2006) 33-41.

[52] M. Venkatesan, D.A. Kuntz, D.R. Rose, Human lysosomal alpha-mannosidases exhibit different inhibition and metal binding properties, Protein Sci. Publ. Protein Soc., 18 (2009) 2242-2251.

[53] M. Brini, D. Ottolini, T. Cali, E. Carafoli, Calcium in health and disease, Met. Ions Life Sci., 13 (2013) 81-137.

[54] J.K. Chesters, M. Will, Zinc transport proteins in plasma, Br. J. Nutr., 46 (1981) 111-118.

[55] J. Roth, S. Ponzoni, M. Aschner, Manganese homeostasis and transport, Met. Ions Life Sci., 12 (2013) 169-201.

[56] R.A. Gibbons, S.N. Dixon, K. Hallis, A.M. Russell, B.F. Sansom, H.W. Symonds, Manganese metabolism in cows and goats, Biochim. Biophys. Acta, 444 (1976) 1-10.

[57] J.A. Roth, Homeostatic and toxic mechanisms regulating manganese uptake, retention, and elimination, Biol. Res., 39 (2006) 45-57.

[58] G. Isani, E. Carpenè, Metallothioneins, unconventional proteins from unconventional animals: a long journey from nematodes to mammals, Biomolecules, 4 (2014) 435-457. Calcium, 50 (2011) 184-192.

[60] P. Novák, T. Soukup, Calsequestrin distribution, structure and function, its role in normal and pathological situations and the effect of thyroid hormones, Physiol. Res., 60 (2011) 439-452.

[61] D.B. Williams, Beyond lectins: the calnexin/calreticulin chaperone system of the endoplasmic reticulum, J. Cell Sci., 119 (2006) 615-623. 
exchanging pool of Ca2+, J. Biol. Chem., 272 (1997) 30873-30879.

[63] R.E. Milner, S. Baksh, C. Shemanko, M.R. Carpenter, L. Smillie, J.E. Vance, M. Opas, M. Michalak, Calreticulin, and not calsequestrin, is the major calcium binding protein of smooth muscle sarcoplasmic reticulum and liver endoplasmic reticulum, J. Biol. Chem., 266 (1991) 7155-7165.

[64] B. Honoré, H. Vorum, The CREC family, a novel family of multiple EF-hand, low-affinity Ca(2+)binding proteins localised to the secretory pathway of mammalian cells, FEBS Lett., 466 (2000) 11-18. [65] G.K. Aradhyam, L.M. Balivada, M. Kanuru, P. Vadivel, B.S. Vidhya, Calnuc: Emerging roles in calcium signaling and human diseases, IUBMB Life, 62 (2010) 436-446.

[66] V.M. Morel-Huaux, M. Pypaert, S. Wouters, A.M. Tartakoff, U. Jurgan, K. Gevaert, P.J. Courtoy, The calcium-binding protein p54/NEFA is a novel luminal resident of medial Golgi cisternae that traffics independently of mannosidase II, Eur. J. Cell Biol., 81 (2002) 87-100.

[67] K.G. Baimbridge, M.R. Celio, J.H. Rogers, Calcium-binding proteins in the nervous system, Trends Neurosci., 15 (1992) 303-308.

[68] K. Kalia, W. Jiang, W. Zheng, Manganese accumulates primarily in nuclei of cultured brain cells, Neurotoxicology, 29 (2008) 466-470.

[69] F.C. Wedler, B.W. Ley, A.A. Grippo, Manganese(II) dynamics and distribution in glial cells cultured from chick cerebral cortex, Neurochem. Res., 14 (1989) 1129-1135.

[70] M. Aschner, M. Gannon, H.K. Kimelberg, Manganese uptake and efflux in cultured rat astrocytes, J. Neurochem., 58 (1992) 730-735.

[71] A. Carmona, G. Devès, S. Roudeau, P. Cloetens, S. Bohic, R. Ortega, Manganese Accumulates

within Golgi Apparatus in Dopaminergic Cells as Revealed by Synchrotron X-rayFluorescence Nanoimaging, Cjem. Neurosci., 1 (2010) 194-203

[72] S. Das, K. Khatua, A. Rakshit, A. Carmona, A. Sarkar, S. Bakthavatsalam, R. Ortega, A. Datta, Emerging chemical tools and techniques for tracking biological manganese, Dalton Trans. Camb. Engl. 2003, 48 (2019) 7047-7061.

[73] D.E Ash, V.L. Schramm, Determination of free and bound manganese(II) in hepatocytes from fed and faster rats, J. Biol. Chem., 257 (1982) 9261-9264

[74] J.M. Argüello, D. Raimunda, M. González-Guerrero, Metal transport across biomembranes: emerging models for a distinct chemistry, J. Biol. Chem., 287 (2012) 13510-13517.

[75] Zheng J, Trudeau M.C., Handbook of Ion Channels, CRC Press, n.d. 
[76] Arguello J., Lutsenko S., Metal Transporters, 1st ed., Academic Press, n.d.

[77] T.W. Clarkson, Metal toxicity in the central nervous system, Environ. Health Perspect., 75 (1987) 59-64.

[78] B.B. Williams, G.F. Kwakye, M. Wegrzynowicz, D. Li, M. Aschner, K.M. Erikson, A.B. Bowman, Altered manganese homeostasis and manganese toxicity in a Huntington's disease striatal cell model are not explained by defects in the iron transport system, Toxicol. Sci. Off. J. Soc. Toxicol., 117 (2010) 169-179.

[79] D.J. Bonda, H. Lee, J.A. Blair, X. Zhu, G. Perry, M.A. Smith, Role of Metal Dyshomeostasis in Alzheimer Disease, Met. Integr. Biometal Sci., 3 (2011) 267-270.

[80] R.J. Ward, F.A. Zucca, J.H. Duyn, R.R. Crichton, L. Zecca, The role of iron in brain ageing and neurodegenerative disorders, Lancet Neurol., 13 (2014) 1045-1060.

[81] A.C. Martins, P. Morcillo, O.M. Ijomone, V. Venkataramani, F.E. Harrison, E. Lee, A.B. Bowman, Int. J. Environ. Res. Public. Health, 16 (2019).

[82] T.V. Peres, M.R.C. Schettinger, P. Chen, F. Carvalho, D.S. Avila, A.B. Bowman, M. Aschner, "Manganese-induced neurotoxicity: a review of its behavioral consequences and neuroprotective strategies," BMC Pharmacol. Toxicol., 17 (2016).

[83] Y. Hirata, K. Kiuchi, T. Nagatsu, Manganese mimics the action of 1-methyl-4-phenylpyridinium ion, a dopaminergic neurotoxin, in rat striatal tissue slices, Neurosci. Lett., 311 (2001) 53-56.

[84] A. Putrament, H. Baranowska, A. Ejchart, W. Jachymczyk, Manganese mutagenesis in yeast VI $\mathrm{Mn2}+$ uptake, mitDNA replication and ER induction: comparison with other divalent cations, Mol. Gen. Genet. MGG, 151 (1977) 69-76.

[85] S. Anagianni, K. Tuschl, Genetic Disorders of Manganese Metabolism, Curr. Neurol. Neurosci., 19 (2019) 1534-6293

[86] Y. Nishito, N. Tsuji, H. Fujishiro, T.-A. Takeda, T. Yamazaki, F. Teranishi, F. Okazaki, A. Matsunaga, K. Tuschl, R. Rao, S. Kono, H. Miyajima, H. Narita, S. Himeno, T. Kambe, Direct Comparison of Manganese Detoxification/Efflux Proteins and Molecular Characterization of ZnT10 Protein as a Manganese Transporter, J. Biol. Chem., 291 (2016) 14773-14787.

[87] D. Leyva-IIlades, P. Chen, C.E. Zogzas, S. Hutchens, J.M. Mercado, C.D. Swaim, R.A. Morrisett, transporter, and parkinsonism-causing mutations block its intracellular trafficking and efflux activity, 
[88] S. Mukhopadhyay, C. Bachert, D.R. Smith, A.D. Linstedt, Manganese-induced trafficking and turnover of the cis-Golgi glycoprotein GPP130, Mol. Biol. Cell, 21 (2010) 1282-1292.

[89] X. Yang, Y. Xu, Mutations in the ATP13A2 Gene and Parkinsonism: A Preliminary Review, BioMed Res. Int., 2014 (2014).

[90] S. van Veen, S. Martin, C. Van den Haute, V. Benoy, J. Lyons, R. Vanhoutte, J.P. Kahler, J-P. Decuypere, G. Gelders, E. Lambie, J. Zielich, J.V. Swinnen, W. Annaert, P. Agostinis, B. Ghesquière, S. Verhelst, V. Baekelandt, J. Eggermont, P. Vangheluwe, ATP13A2 deficiency disrupts lysosomal polyamine export, Nature, 578 (2020) 419-424

[91] V. Nikoletopoulou, N. Tavernarakis, The PMR1 pump in alpha-synuclein toxicity and .305 neurodegeneration, Neurosci. Lett., 663 (2018) 66-71.

[92] B. Szewczyk, Zinc homeostasis and neurodegenerative disorders, Front. Aging Neurosci., 5 307 (2013) 33.

[93] R. Gomez-Villafuertes, B. Mellström, J.R. Naranjo, Searching for a role of NCX/NCKX exchangers in neurodegeneration, Mol. Neurobiol., 35 (2007) 195-202.

[94] H. Tu, O. Nelson, A. Bezprozvanny, Z. Wang, S.-F. Lee, Y.-H. Hao, L. Serneels, B. De Strooper, G. Yu, I. Bezprozvanny, Presenilins form ER Ca2+ leak channels, a function disrupted by familial Alzheimer's disease-linked mutations, Cell, 126 (2006) 981-993.

[95] G. Carmeliet, S. Van Cromphaut, E. Daci, C. Maes, R. Bouillon, Disorders of calcium homeostasis, Best Pract. Res. Clin. Endocrinol. Metab., 17 (2003) 529-546.

[96] K.P. Schlingmann, M. Konrad, H.W. Seyberth, Genetics of hereditary disorders of magnesium homeostasis, Pediatr. Nephrol. Berl. Ger., 19 (2004) 13-25.

[97] A. Sakuntabhai, V. Ruiz-Perez, S. Carter, N. Jacobsen, S. Burge, S. Monk, M. Smith, C.S. Munro, M. O'Donovan, N. Craddock, R. Kucherlapati, J.L. Rees, M. Owen, G.M. Lathrop, A.P. Monaco, T. Strachan, A. Hovnanian, Mutations in ATP2A2, encoding a Ca2+ pump, cause Darier disease, Nat. Genet., 21 (1999) 271-277.

[98] R. Sudbrak, J. Brown, C. Dobson-Stone, S. Carter, J. Ramser, J. White, E. Healy, M. Dissanayake, Hailey-Hailey disease is caused by mutations in ATP2C1 encoding a novel $\mathrm{Ca}(2+)$ pump, Hum. Mol. Genet., 9 (2000) 1131-1140.

[99] L. Missiaen, L. Raeymaekers, L. Dode, J. Vanoevelen, K. Van Baelen, J.B. Parys, G. Callewaert, 
H. De Smedt, S. Segaert, F. Wuytack, SPCA1 pumps and Hailey-Hailey disease, Biochem. Biophys. Res. Commun., 322 (2004) 1204-1213.

[100] S. Leitch, M. Feng, S. Muend, L.T. Braiterman, A.L. Hubbard, R. Rao, Vesicular distribution of Secretory Pathway Ca2+-ATPase isoform 1 and a role in manganese detoxification in liver-derived polarized cells, Biometals Int. J. Role Met. Ions Biol. Biochem. Med., 24 (2011) 159-170.

[101] S. Mukhopadhyay, A.D. Linstedt, Identification of a gain-of-function mutation in a Golgi P-type ATPase that enhances Mn2+ efflux and protects against toxicity, Proc. Natl. Acad. Sci. U. S. A., 108 (2011) 858-863.

[102] T. Kambe, A. Hashimoto, S. Fujimoto, Current understanding of ZIP and ZnT zinc transporters in human health and diseases, Cell. Mol. Life Sci. CMLS, 71 (2014) 3281-3295.

[103] G. Schmitt-Ulms, S. Ehsani, J.C. Watts, D. Westaway, H. Wille, Evolutionary descent of prion genes from the ZIP family of metal ion transporters, PloS One, 4 (2009) e7208.

[105] R. Peanne, P. de Lonlay, F. Foulquier, U. Kornak, D.J. Lefeber, E. Morava, B. Perez, N. Seta, C. Thiel, E. Van Schaftingen, G. Matthijs, J. Jaeken, Congenital disorders of glycosylation (CDG): Quo vadis?, Eur. J. Med. Genet., (2017).

[106] J. Jaeken, G. Matthijs, Congenital disorders of glycosylation: a rapidly expanding disease family, Annu. Rev. Genomics Hum. Genet., 8 (2007) 261-278.

[107] H.H. Freeze, Congenital Disorders of Glycosylation: CDG-I, CDG-II, and beyond, Curr. Mol. Med., 7 (2007) 389-396.

[108] Y. Nevo, N. Nelson, The NRAMP family of metal-ion transporters, Biochim. Biophys. Acta, 1763 (2006) 609-620.

[109] T. Vasanthakumar, J.L. Rubinstein, Structure and Roles of V-type ATPases, Trends Biochem. Sci., (2020).

[110] U. Kornak, E. Reynders, A. Dimopoulou, J. van Reeuwijk, B. Fischer, A. Rajab, B. Budde, P. Nürnberg, F. Foulquier, ARCL Debré-type Study Group, D. Lefeber, Z. Urban, S. Gruenewald, W. Annaert, H.G. Brunner, H. van Bokhoven, R. Wevers, E. Morava, G. Matthijs, L. Van Maldergem, et al., Impaired glycosylation and cutis laxa caused by mutations in the vesicular H+-ATPase subunit ATP6V0A2, Nat. Genet., 40 (2008) 32-34.

[111] F. Foulquier, M. Amyere, J. Jaeken, R. Zeevaert, E. Schollen, V. Race, R. Bammens, W. Morelle, 

Freeze, E. Van Schaftingen, M. Vikkula, G. Matthijs, TMEM165 Deficiency Causes a Congenital Disorder of Glycosylation, Am. J. Hum. Genet., 91 (2012) 15-26.

[112] J.H. Park, M. Hogrebe, M. Gruneberg, I. DuChesne, A.L. von der Heiden, J. Reunert, K.P. Schlingmann, K.M. Boycott, C.L. Beaulieu, A.A. Mhanni, A.M. Innes, K. Hortnagel, S. Biskup, E.M. Gleixner, G. Kurlemann, B. Fiedler, H. Omran, F. Rutsch, Y. Wada, K. Tsiakas, et al., SLC39A8 Deficiency: A Disorder of Manganese Transport and Glycosylation, Am. J. Hum. Genet., 97 (2015) 894-903. Keldermans, E. Souche, A. Corveleyn, R. Sparkes, K. Bhattacharya, C. Devalck, R. Schrijvers, F. Foulquier, R. Gilmore, G. Matthijs, Mutations in MAGT1 lead to a glycosylation disorder with a variable phenotype, Proc. Natl. Acad. Sci. U. S. A., (2019).

[114] M. Garshasbi, V. Hadavi, H. Habibi, K. Kahrizi, R. Kariminejad, F. Behjati, A. Tzschach, H. 369 Najmabadi, H.H. Ropers, A.W. Kuss, A defect in the TUSC3 gene is associated with autosomal recessive mental retardation, Am. J. Hum. Genet., 82 (2008) 1158-1164.

[115] F-Y. Li, B. Chaigne-Delalande, H. Su, G. Uzel, H. Matthews, M.J. Lenardo, XMEN disease: a new primary immunodeficiency affecting Mg2+ regulation of immunity against Epstein-Barr virus, Blood, 123 (2014) 2148-2152

[116] N. Cherepanova, S. Shrimal, R. Gilmore, N-linked glycosylation and homeostasis of the endoplasmic reticulum, Curr. Opin. Cell Biol., 41 (2016) 57-65.

[117] X.-P. Dong, X. Wang, H. Xu, TRP channels of intracellular membranes, J. Neurochem., 113 (2010) 313-328.

[118] B.T. Bedenk, S. Almeida-Corrêa, A. Jurik, N. Dedic, B. Grünecker, A.J. Genewsky, S.F. Kaltwasser, C.J. Riebe, J.M. Deussing, M. Czisch, C.T. Wotjak, Mn2+ dynamics in manganese-enhanced MRI (MEMRI): Cav12 channel-mediated uptake and preferential accumulation in projection terminals, Neurolmage, 169 (2018) 374-382.

[119] J.R. Forbes, P. Gros, Iron, manganese, and cobalt transport by Nramp1 (Slc11a1) and Nramp2 (Slc11a2) expressed at the plasma membrane, Blood, 102 (2003) 1884-1892.

[120] Y. Xin, H. Gao, J. Wang, Y. Qiang, M.U. Imam, Y. Li, J. Wang, R. Zhang, H. Zhang, Y. Yu, H. Wang, H. Luo, C. Shi, Y. Xu, S. Hojyo, T. Fukada, J. Min, F. Wang, Manganese transporter Slc39a14 deficiency revealed its key role in maintaining manganese homeostasis in mice, Cell Discov., 3 (2017) 17025.

[121] M.E. Techau, J. Valdez-Taubas, J.-F. Popoff, R. Francis, M. Seaman, J.M. Blackwell, Evolution of differences in transport function in SIc11a family members, J. Biol. Chem., 282 (2007) 35646-35656. 
[122] M.F.M. Cellier, Nramp: from sequence to structure and mechanism of divalent metal import, Curr. Top. Membr., 69 (2012) 249-293.

[123] J.W. Finley, C.D. Davis, Manganese deficiency and toxicity: are high or low dietary amounts of manganese cause for concern?, BioFactors Oxf. Engl., 10 (1999) 15-24.

[124] P. Chen, J. Bornhorst, M. Aschner, Manganese metabolism in humans, Front. Biosci. Landmark Ed., 23 (2018) 1655-1679.

[125] J.W. Finley, P.E. Johnson, L.K. Johnson, Sex affects manganese absorption and retention by humans from a diet adequate in manganese, Am. J. Clin. Nutr., 60 (1994) 949-955.

[126] Q. Ye, J.E. Park, K. Gugnani, S. Betharia, A. Pino-Figueroa, J. Kim, Influence of iron metabolism on manganese transport and toxicity, Met. Integr. Biometal Sci., 9 (2017) 1028-1046.

[127] L. Davidsson, A. Cederblad, B. Lönnerdal, B. Sandström, The effect of individual dietary components on manganese absorption in humans, Am. J. Clin. Nutr., 54 (1991) 1065-1070.

[128] C. Au, A. Benedetto, M. Aschner, Manganese transport in eukaryotes: the role of DMT1, Neurotoxicology, 29 (2008) 569-576.

[129] P. Ponka, C.N. Lok, The transferrin receptor: role in health and disease, Int. J. Biochem. Cell Biol., 31 (1999) 1111-1137.

[130] T.E. Gunter, B. Gerstner, K.K. Gunter, J. Malecki, R. Gelein, W.M. Valentine, M. Aschner, D.I. 406 Yule, Manganese transport via the transferrin mechanism, Neurotoxicology, 34 (2013) 118-127.

[131] L. Davidsson, B. Lönnerdal, B. Sandström, C. Kunz, C.L. Keen, Identification of transferrin as the major plasma carrier protein for manganese introduced orally or intravenously or after in vitro addition 409 in the rat, J. Nutr., 119 (1989) 1461-1464.

[132] P. Chen, S. Chakraborty, S. Mukhopadhyay, E. Lee, M.M.B. Paoliello, A.B. Bowman, M. Aschner, Manganese homeostasis in the nervous system, J. Neurochem., 134 (2015) 601-610. Manganese, but not its Loading onto Transferrin, Toxicol. Sci., 107 (2009) 182-193. 198. In Vivo, Int. J. Mol. Sci., 18 (2017). 
W.K. Chong, T.S. Jacques, R.L. Woltjer, S. Eaton, A. Gregory, L. Sanford, E. Kara, H. Houlden, S.M. Cuno, H. Prokisch, L. Valletta, V. Tiranti, et al., Mutations in SLC39A14 disrupt manganese homeostasis and cause childhood-onset parkinsonism-dystonia, Nat. Commun., 7 (2016) 11601.

[137] I.F. Scheiber, Y. Wu, S.E. Morgan, N. Zhao, The intestinal metal transporter ZIP14 maintains systemic manganese homeostasis, J. Biol. Chem., (2019).

[138] N. Zhao, J. Gao, C.A. Enns, M.D. Knutson, ZRT/IRT-like protein 14 (ZIP14) promotes the cellular assimilation of iron from transferrin, J. Biol. Chem., 285 (2010) 32141-32150.

[139] W. Lin, D.R. Vann, P.-T. Doulias, T. Wang, G. Landesberg, X. Li, E. Ricciotti, R. Scalia, M. He, N.J. Hand, D.J. Rader, Hepatic metal ion transporter ZIP8 regulates manganese homeostasis and manganese-dependent enzyme activity, J. Clin. Invest., 127 (2017) 2407-2417.

[140] E.-K. Choi, T.-T. Nguyen, N. Gupta, S. Iwase, Y.A. Seo, Functional analysis of SLC39A8 mutations and their implications for manganese deficiency and mitochondrial disorders, Sci. Rep., 8 (2018) 3163. Ferroportin is a manganese-responsive protein that decreases manganese cytotoxicity and accumulation, J. Neurochem., 112 (2010) 1190-1198.

[142] C.E. Gavin, K.K. Gunter, T.E. Gunter, Manganese and calcium transport in mitochondria: implications for manganese toxicity, Neurotoxicology, 20 (1999) 445-453.

[143] E. Dulary, S. Potelle, D. Legrand, F. Foulquier, TMEM165 deficiencies in Congenital Disorders homeostasis, Tissue Cell, 49 (2017) 150-156.

[144] Y. Cohen, M. Megyeri, O.C.W. Chen, G. Condomitti, I. Riezman, U. Loizides-Mangold, A. Abdul440 Sada, N. Rimon, H. Riezman, F.M. Platt, A.H. Futerman, M. Schuldiner, The yeast p5 type ATPase, spf1, regulates manganese transport into the endoplasmic reticulum, PloS One, 8 (2013) e85519.

[145] S.-I. Yonekura, C. Toyoshima, $\mathrm{Mn}(2+)$ transport by $\mathrm{Ca}(2+)-$ ATPase of sarcoplasmic reticulum, FEBS Lett., 590 (2016) 2086-2095.

[146] D.M. Sørensen, T. Holemans, S. van Veen, S. Martin, T. Arslan, I.W. Haagendahl, H.W. Holen, N.N. Hamouda, J. Eggermont, M. Palmgren, P. Vangheluwe, Parkinson disease related ATP13A2 evolved early in animal evolution, PloS One, 13 (2018) e0193228.

[147] M. Micaroni, G. Perinetti, C.P. Berrie, A.A. Mironov, The SPCA1 Ca2+ Pump and Intracellular Membrane Trafficking, Traffic, 11 (2010) 1315-1333.

[148] A.R. Reddi, L.T. Jensen, V.C. Culotta, Manganese homeostasis in Saccharomyces cerevisiae, 
Chem. Rev., 109 (2009) 4722-4732.

[149] I. Vandecaetsbeek, P. Vangheluwe, L. Raeymaekers, F. Wuytack, J. Vanoevelen, The Ca2+ Pumps of the Endoplasmic Reticulum and Golgi Apparatus, Cold Spring Harb. Perspect. Biol., 3 (2011).

[150] M. Xiang, D. Mohamalawari, R. Rao, A novel isoform of the secretory pathway Ca2+, $\mathrm{Mn}(2+)-$ ATPase, hSPCA2, has unusual properties and is expressed in the brain, J. Biol. Chem., 280 (2005) $11608-11614$.

[151] C. Kienzle, N. Basnet, A.H. Crevenna, G. Beck, B. Habermann, N. Mizuno, J. von Blume, Cofilin recruits F-actin to SPCA1 and promotes Ca2+-mediated secretory cargo sorting, J. Cell Biol., 206 (2014) $635-654$.

[152] S. Potelle, W. Morelle, E. Dulary, S. Duvet, D. Vicogne, C. Spriet, M.-A. Krzewinski-Recchi, P. Morsomme, J. Jaeken, G. Matthijs, G. De Bettignies, F. Foulquier, Glycosylation abnormalities in Gdt1p/TMEM165 deficient cells result from a defect in Golgi manganese homeostasis, Hum. Mol. Genet., 25 (2016) 1489-1500.

[153] D. Demaegd, F. Foulquier, A.-S. Colinet, L. Gremillon, D. Legrand, P. Mariot, E. Peiter, E. Van Schaftingen, G. Matthijs, P. Morsomme, Newly characterized Golgi-localized family of proteins is involved in calcium and pH homeostasis in yeast and human cells, Proc. Natl. Acad. Sci., 110 (2013) 6859-6864.

[154] D. Demaegd, A.-S. Colinet, A. Deschamps, P. Morsomme, Molecular evolution of a novel family of putative calcium transporters, PloS One, 9 (2014) e100851.

[155] M. Eisenhut, N. Hoecker, S.B. Schmidt, R.M. Basgaran, S. Flachbart, P. Jahns, T. Eser, S. Geimer, TRANSPORTER1 Is Essential for Manganese Homeostasis in Arabidopsis, Mol. Plant, 11 (2018) 955969.

[156] N. Hoecker, A. Honke, K. Frey, D. Leister, A. Schneider, Homologous Proteins of the Manganese Transporter PAM71 Are Localized in the Golgi Apparatus and Endoplasmic Reticulum, Plants Basel Switz., 9 (2020).

[157] R. Zeinert, E. Martinez, J. Schmitz, K. Senn, B. Usman, V. Anantharaman, L. Aravind, L.S. Waters, Structure-function analysis of manganese exporter proteins across bacteria, J. Biol. Chem., (2018).

[158] C. Gandini, S.B. Schmidt, S. Husted, A. Schneider, D. Leister, The transporter SynPAM71 is located in the plasma membrane and thylakoids, and mediates manganese tolerance in Synechocystis PCC6803, New Phytol., 215 (2017) 256-268. 

Synechocystis Manganese Exporter Mnx Is Essential for Manganese Homeostasis in Cyanobacteria, Plant Physiol., 173 (2017) 1798-1810.

[160] A. Schneider, I. Steinberger, A. Herdean, C. Gandini, M. Eisenhut, S. Kurz, A. Morper, N. Hoecker, T. Rühle, M. Labs, U.-I. Flügge, S. Geimer, S.B. Schmidt, S. Husted, A.P.M. Weber, C. Spetea, for Efficient Manganese Uptake at the Thylakoid Membrane in Arabidopsis, Plant Cell, 28 (2016) 892910.

[161] C. Rosnoblet, D. Legrand, D. Demaegd, H. Hacine-Gherbi, G. de Bettignies, R. Bammens, C. Borrego, S. Duvet, P. Morsomme, G. Matthijs, F. Foulquier, Impact of disease-causing mutations on TMEM165 subcellular localization, a recently identified protein involved in CDG-II, Hum. Mol. Genet., 22 (2013) 2914-2928.

[162] M.-A. Krzewinski-Recchi, S. Potelle, A.-M. Mir, D. Vicogne, E. Dulary, S. Duvet, W. Morelle, G. de Bettignies, F. Foulquier, Evidence for splice transcript variants of TMEM165, a gene involved in CDG, Biochim. Biophys. Acta BBA - Gen. Subj., 1861 (2017) 737-748.

[163] S. Schulte Althoff, M. Grüneberg, J. Reunert, J.H. Park, S. Rust, C. Mühlhausen, Y. Wada, R. .497 Santer, T. Marquardt, TMEM165 Deficiency: Postnatal Changes in Glycosylation, JIMD Rep., 26 (2016) 21-29.

[164] R. Bammens, N. Mehta, V. Race, F. Foulquier, J. Jaeken, M. Tiemeyer, R. Steet, G. Matthijs, H. .500 Flanagan-Steet, Abnormal cartilage development and altered N-glycosylation in Tmem165-deficient zebrafish mirrors the phenotypes associated with TMEM165-CDG, Glycobiology, 25 (2015) 669-682. E.-J. Kamsteeg, S.Y. Wong, M. van Scherpenzeel, P. Jamali, U. Brandt, L. Nijtmans, et al., Mutations in ATP6V1E1 or ATP6V1A Cause Autosomal-Recessive Cutis Laxa, Am. J. Hum. Genet., 100 (2017) 216227.

[167] J.C. Jansen, S. Timal, M. van Scherpenzeel, H. Michelakakis, D. Vicogne, A. Ashikov, M. Moraitou, A. Hoischen, K. Huijben, G. Steenbergen, M.A.W. van den Boogert, F. Porta, P.L. Calvo, M. Mavrikou, G. Cenacchi, G. van den Bogaart, J. Salomon, A.G. Holleboom, R.J. Rodenburg, J.P.H. Drenth, et al., TMEM199 Deficiency Is a Disorder of Golgi Homeostasis Characterized by Elevated Aminotransferases, Alkaline Phosphatase, and Cholesterol and Abnormal Glycosylation, Am. J. Hum. 
[168] R. Zeevaert, F. de Zegher, L. Sturiale, D. Garozzo, M. Smet, M. Moens, G. Matthijs, J. Jaeken, Bone Dysplasia as a Key Feature in Three Patients with a Novel Congenital Disorder of Glycosylation (CDG) Type II Due to a Deep Intronic Splice Mutation in TMEM165, JIMD Rep., 8 (2013) 145-152.

[169] B. Xia, W. Zhang, X. Li, R. Jiang, T. Harper, R. Liu, R.D. Cummings, M. He, Serum N-glycan and O-glycan analysis by mass spectrometry for diagnosis of congenital disorders of glycosylation, Anal. Biochem., 442 (2013) 178-185.

[170] A.-S. Colinet, P. Sengottaiyan, A. Deschamps, M.-L. Colsoul, L. Thines, D. Demaegd, M.-C. required for stress-induced calcium signaling and protein glycosylation, Sci. Rep., 6 (2016) 24282.

[171] W. Morelle, S. Potelle, P. Witters, S. Wong, L. Climer, V. Lupashin, G. Matthijs, T. Gadomski, J. Jaeken, D. Cassiman, E. Morava, F. Foulquier, Galactose Supplementation in Patients With TMEM165CDG Rescues the Glycosylation Defects, J. Clin. Endocrinol. Metab., 102 (2017) 1375-1386.

[172] L. Thines, A. Deschamps, P. Sengottaiyan, O. Savel, J. Stribny, P. Morsomme, The yeast protein (2018).

[173] H. Wang, Y. Yang, F. Huang, Z. He, P. Li, W. Zhang, W. Zhang, B. Tang, In situ Fluorescent and Photoacoustic Imaging of Golgi pH to Elucidate the Function of Transmembrane Protein 165, Anal. Chem., (2020).

[174] N.A. Snyder, C.P. Stefan, C.T. Soroudi, A. Kim, C. Evangelista, K.W. Cunningham, $\mathrm{H}^{+}$and Pi Byproducts of Glycosylation Affect $\mathrm{Ca}^{2+}$ Homeostasis and Are Retrieved from the Golgi Complex by Homologs of TMEM165 and XPR1, G3amp58 GenesGenomesGenetics, 7 (2017) 3913-3924.

[175] S. Venkat, A.D. Linstedt, Manganese-induced trafficking and turnover of GPP130 is mediated by sortilin, Mol. Biol. Cell, 28 (2017) 2569-2578.

[176] S. Potelle, E. Dulary, L. Climer, S. Duvet, W. Morelle, D. Vicogne, E. Lebredonchel, M. Houdou, C. Spriet, M.-A. Krzewinski-Recchi, R. Peanne, A. Klein, G. de Bettignies, P. Morsomme, G. Matthijs, T. Marquardt, V. Lupashin, F. Foulquier, Manganese-induced turnover of TMEM165, Biochem. J., 474 (2017) 1481-1493. 
[178] N.A. Snyder, M.V. Palmer, T.A. Reinhardt, K.W. Cunningham, Milk biosynthesis requires the Golgi cation exchanger TMEM165, J. Biol. Chem., (2019).

[179] T.A. Reinhardt, J.D. Lippolis, R.E. Sacco, The $\mathrm{Ca}(2+) / \mathrm{H}(+)$ antiporter TMEM165 expression, localization in the developing, lactating and involuting mammary gland parallels the secretory pathway $\mathrm{Ca}(2+)$ ATPase (SPCA1), Biochem. Biophys. Res. Commun., 445 (2014) 417-421.

[180] A.-S. Colinet, L. Thines, A. Deschamps, G. Flémal, D. Demaegd, P. Morsomme, Acidic and uncharged polar residues in the consensus motifs of the yeast Ca2+transporter Gdt1p are required for calcium transport, Cell. Microbiol., 19 (2017).

[181] E. Lebredonchel, M. Houdou, S. Potelle, G. de Bettignies, C. Schulz, M.-A. Krzewinski Recchi, V. Lupashin, D. Legrand, A. Klein, F. Foulquier, Dissection of TMEM165 function in Golgi glycosylation and its Mn2+ sensitivity, Biochimie, 165 (2019) 123-130.

[182] J. Chen, S. Smaardijk, C-A. Mattelaer, F. Pamula, I. Vandecaetsbeek, J. Vanoevelen, F. Wuytack, E. Lescrinier, J. Eggermont, P. Vangheluwe, An N-terminal Ca2+-binding motif regulates the secretory pathway Ca2+/Mn2+-transport ATPase SPCA1, J. Biol. Chem., 294 (2019) 7878-7891

[183] D. Radisky, J. Kaplan, Regulation of transition metal transport across the yeast plasma membrane, J. Biol. Chem., 274 (1999) 4481-4484.

[184] K.J. Thompson, M. Wessling-Resnick, ZIP14 is degraded in response to manganese exposure, Biometals Int. J. Role Met. Ions Biol. Biochem. Med., (2019).

[185] E. Lebredonchel, M. Houdou, H.-H. Hoffmann, K. Kondratska, M.-A. Krzewinski, D. Vicogne, C.M. Rice, A. Klein, F. Foulquier, Investigating the functional link between TMEM165 and SPCA1, Biochem. J., (2019).

[186] E. Dulary, S.-Y. Yu, M. Houdou, G. de Bettignies, V. Decool, S. Potelle, S. Duvet, M.-A. 566 Krzewinski-Recchi, A. Garat, G. Matthijs, Y. Guerardel, F. Foulquier, Investigating the function of Gdt1p in yeast Golgi glycosylation, Biochim. Biophys. Acta BBA - Gen. Subj., 1862 (2018) 394-402. Gasnier, S. Potelle, F. Foulquier, Involvement of thapsigargin and cyclopiazonic acid-sensitive pumps in the rescue of TMEM165-associated glycosylation defects by Mn2, FASEB J. Off. Publ. Fed. Am. Soc. Exp. Biol., (2018) fj201800387R. Golgi ion pump Pmr1 supplies the yeast secretory pathway with $\mathrm{Ca} 2+$ and $\mathrm{Mn} 2+$ required for glycosylation, sorting, and endoplasmic reticulum-associated protein degradation, Mol. Biol. Cell, 9 (1998) 1149-1162. 
[189] N.J. Foot, H.E. Dalton, L.M. Shearwin-Whyatt, L. Dorstyn, S.-S. Tan, B. Yang, S. Kumar, Regulation of the divalent metal ion transporter DMT1 and iron homeostasis by a ubiquitin-dependent mechanism involving Ndfips and WWP2, Blood, 112 (2008) 4268-4275.

[190] C. Burd, P.J. Cullen, Retromer: a master conductor of endosome sorting, Cold Spring Harb. Perspect. Biol., 6 (2014).

[191] H. Gao, W. Xie, C. Yang, J. Xu, J. Li, H. Wang, X. Chen, C.-F. Huang, NRAMP2, a trans-Golgi network-localized manganese transporter, is required for Arabidopsis root growth under manganese deficiency, New Phytol., 217 (2018) 179-193.

[192] T. Hirayama, M. Inden, H. Tsuboi, M. Niwa, Y. Uchida, Y. Naka, I. Hozumi, H. Nagasawa, A Golgitargeting fluorescent probe for labile Fe(ii) to reveal an abnormal cellular iron distribution induced by dysfunction of VPS35, Chem. Sci., 10 (2019) 1514-1521. Gersdorf, J. Amiel, B. Nur, I. Stolte-Dijkstra, A.M. van Eerde, K.L. van Gassen, C.C. Breugem, A. a skeletal dysplasia with amelogenesis imperfecta mediated by GAG biosynthesis defects, Nat. 
Table 1 (Foulquier \& Legrand)

\begin{tabular}{|c|c|c|c|c|}
\hline Family & $\begin{array}{l}\text { Name } \\
\text { (Common alias) }\end{array}$ & $\begin{array}{l}\text { Transported } \\
\text { biometals }\end{array}$ & $\begin{array}{l}\text { Primary/ } \\
\text { secondary } \\
\text { location }\end{array}$ & $\begin{array}{l}\text { Influx (I) } \\
\text { or } \\
\text { Efflux (E) }\end{array}$ \\
\hline CALHM-C & CALHM2 (FAM26B) & Ca, non select. & PM & 1 \\
\hline CRAC-C & ORAI1 (CRACM1) & $\mathrm{Ca}$ & PM & 1 \\
\hline$\overline{\mathrm{CaTA}}$ & TMBIM6 (BI-1) & $\mathrm{Ca}$ & ER/PM/Mito. & 1 \\
\hline Flower & CACFD1 (Flower) & $\mathrm{Ca}$ & PM & 1 \\
\hline \multirow{2}{*}{ Innexin } & PANX1 (MRS1) & $\mathrm{Ca}$, non select. & ER/PM & 1 \\
\hline & MRS2 & $\mathrm{Mg}$ & Mito & 1 \\
\hline \multirow[t]{2}{*}{$\underline{\text { MagT1 }}$} & MAGT1 & $\mathrm{Mg}$ & ER/PM & 1 \\
\hline & TUSC3 & Mg & ER & 1 \\
\hline$\underline{\mathrm{MMgT}}$ & MMGT1 & Mg & ER/Golgi/PM/Endos. & 1 \\
\hline$\underline{\mathrm{MLKL}}$ & MLKL & $\mathrm{Mg}$ & PM & 1 \\
\hline \multirow[t]{3}{*}{$\underline{\text { MPP }}$} & VDAC1 & $\mathrm{Ca}$, non select. & Mito./PM & $\mathrm{E}$ \\
\hline & VDAC2 & Ca, non select. & Mito. & $\mathrm{E}$ \\
\hline & VDAC3 & Ca, non select. & Mito. & $\mathrm{E}$ \\
\hline \multirow[t]{2}{*}{$\underline{\mathrm{P} 2 \mathrm{X}}$} & P2X4 (P2RX4) & $\mathrm{Ca}, \mathrm{K}, \mathrm{Na}$, non select. & PM/Endos. & 1 \\
\hline & P2X7 P2RX7) & $\mathrm{Ca}, \mathrm{K}, \mathrm{Na}$, non select. & PM & 1 \\
\hline \multirow[t]{4}{*}{$\underline{\mathrm{PCC}}$} & PKD1 (TRPP1) & $\mathrm{Ca}, \mathrm{K}, \mathrm{Na}$ & PM/ER/Golgi/Endos. & 1 \\
\hline & PKD2 (TRPP2) & $\mathrm{Ca}, \mathrm{K}, \mathrm{Na}$ & PM/ER/Golgi/Endos. & 1 \\
\hline & TRPML1 (MCOLN1) & $\mathrm{Ca}, \mathrm{Zn}, \mathrm{Fe}, \mathrm{Mn}$, non select. & Endos./PM & 1 \\
\hline & TRPML2 (MCOLN2) & Ca, non select. & Endos./PM & 1 \\
\hline \multirow[t]{2}{*}{$\underline{\text { Presenilin }}$} & PSEN1 (AD3) & $\mathrm{Ca}$ & ER/Golgi/PM/Endos./Mito. & 1 \\
\hline & PSEN2 (AD4) & $\mathrm{Ca}$ & ER/Golgi/PM/Endos. & 1 \\
\hline \multirow[t]{4}{*}{$\underline{\text { RIR-CAC }}$} & IP3R1 (ITPR1) & $\mathrm{Ca}$ & ER/Golgi/PM/Endos. & 1 \\
\hline & IP3R2 (ITPR2) & $\mathrm{Ca}$ & ER/Golgi/PM/Endos. & 1 \\
\hline & IP3R3 (ITPR3) & $\mathrm{Ca}$ & ER/Golgi/PM/Endos. & 1 \\
\hline & RYR3 & $\mathrm{Ca}$ & ER/Golgi/PM/Endos./Mito. & 1 \\
\hline \multirow[t]{7}{*}{ TRP-CC } & TRPC1 (TRP1) & Ca, non select. & PM & 1 \\
\hline & TRPV1 (VR1) & $\mathrm{Ca}$, non select. & PM & 1 \\
\hline & TRPV2 (VRL) & Ca, non select. & PM & 1 \\
\hline & TRPV4 (VRL2) & Ca, non select. & PM & 1 \\
\hline & TRPM2 (EREG1) & $\mathrm{Ca}, \mathrm{Mg}$, non select. & PM/Endos. & 1 \\
\hline & TRPM6 (CHAK2) & $\mathrm{Mg}, \mathrm{Ca}$ & PM & 1 \\
\hline & TRPM7 (CHAK1) & $\mathrm{Ca}, \mathrm{Mg}, \mathrm{Zn}, \mathrm{Mn}$, non select. & PM & 1 \\
\hline \multirow[t]{7}{*}{$\underline{\mathrm{VIC}(\mathrm{VGCC})}$} & CACNA1C (Cav1.2) & $\mathrm{Ca}$ & PM & 1 \\
\hline & CACNA1H (Cav3.3) & $\mathrm{Ca}, \mathrm{Mn}, \mathrm{Fe}, \mathrm{Cd}$ & PM & 1 \\
\hline & CACNA1B (Cav2.2) & $\mathrm{Ca}$ & PM & 1 \\
\hline & CACNA1D (Cav1.3) & $\mathrm{Ca}$ & PM & 1 \\
\hline & CATSPER2 & $\mathrm{Ca}$ & PM & 1 \\
\hline & TPCN1 (TPC1) & $\mathrm{Ca}$ & Endos. & 1 \\
\hline & TPCN2 (TPC2) & $\mathrm{Ca}$ & Endos. & 1 \\
\hline
\end{tabular}

\begin{tabular}{|c|c|c|c|c|}
\hline \multirow{4}{*}{$\mathrm{CaCA}$} & SLC8A1 (NCX1) & $\mathrm{Ca}, \mathrm{Na}$ & PM & $E$ \\
\hline & SLC24A3 (NCKX3) & $\mathrm{Ca}, \mathrm{Na}, \mathrm{K}$ & PM & E \\
\hline & SLC24A4 (NCKX4) & $\mathrm{Ca}, \mathrm{Na}, \mathrm{K}$ & PM & $\mathrm{E}$ \\
\hline & SLC24A6 (NCKX6) & $\mathrm{Ca}, \mathrm{Na}$ & Mito. & । \\
\hline$\underline{\mathrm{CaCA} 2}$ & TMEM165 (TPARL) & $\mathrm{Mn}, \mathrm{Ca}$ & Golgi/Endos. & $\mathrm{E}$ \\
\hline \multirow[t]{9}{*}{$\overline{\mathrm{CDF}}$} & SLC30A1 (Znt1) & $\mathrm{Zn}$ & PM & $\mathrm{E}$ \\
\hline & SLC30A3 (Znt3) & $\mathrm{Zn}$ & PM & $\mathrm{E}$ \\
\hline & SLC30A4 (Znt4) & $\mathrm{Zn}$ & PM & $\mathrm{E}$ \\
\hline & SLC30A5 (Znt5) & $\mathrm{Zn}$ & ER/Golgi & $\mathrm{E}$ \\
\hline & SLC30A6 (Znt6) & $\mathrm{Zn}$ & ER/Golgi & $\mathrm{E}$ \\
\hline & SLC30A7 (Znt7) & $\mathrm{Zn}$ & ER/Golgi & $\mathrm{E}$ \\
\hline & SLC30A9 (Znt9) & $\mathrm{Zn}$ & ER/Golgi & $\mathrm{E}$ \\
\hline & SLC30A10 (Znt10) & $\mathrm{Mn}, \mathrm{Zn}$ & PM & $\mathrm{E}$ \\
\hline & TMEM163 & $\mathrm{Zn}$ & Endos. & $\mathrm{E}$ \\
\hline FPN & SLC40A1 (Ferroportin) & $\mathrm{Mn}, \mathrm{Fe}, \mathrm{Co}, \mathrm{Zn}, \mathrm{Cu}$ & PM & $\mathrm{E}$ \\
\hline LetM1 & LETM1 & $\mathrm{Ca}$ (Mn dependent) & Mito. & $\mathrm{E}$ \\
\hline$\underline{\mathrm{MCU}}$ & MCU & $\mathrm{Ca}, \mathrm{Mn}$ & Mito & $\mathrm{E}$ \\
\hline \multirow[t]{3}{*}{$\underline{\mathrm{MgtE}}$} & SLC41A1 & $\mathrm{Mg}$ & PM/Mito. & $\mathrm{E}$ \\
\hline & SLC41A2 & $\mathrm{Mg}$ & PM & $\mathrm{E}$ \\
\hline & SLC41A3 & $\mathrm{Mg}$ & Mito. & $\mathrm{E}$ \\
\hline $\mathrm{MMgT}$ & MMGT1 & $\mathrm{Mg}$ & ER/Golgi/PM/Endos. & $\mathrm{E}$ \\
\hline \multirow[t]{3}{*}{$\overline{\text { NIPA }}$} & NIPA1 & $\mathrm{Mg}$ & PM & । \\
\hline & NIPA2 & $\mathrm{Mg}$ & PM & । \\
\hline & NIPA3 & $\mathrm{Mg}$ & PM & । \\
\hline \multirow[t]{2}{*}{ NRAMP } & SLC11A1 (NRAMP1) & $\mathrm{Mn}, \mathrm{Fe}$ & PM/Endos. & I \\
\hline & SLC11A2 (DMT1, DCT1) & $\mathrm{Mn}, \mathrm{Zn}, \mathrm{Fe}, \mathrm{Cu}, \mathrm{Cd}, \mathrm{Co}, \mathrm{Ni}, \mathrm{Ca}$ & PM/Endos./mito./Golgi & I \\
\hline \multirow[t]{7}{*}{ P-ATPase } & ATP2A2 (SERCA2) & $\mathrm{Ca}(\mathrm{Mn})$ & ER/Golgi/PM/Endos. & E \\
\hline & ATP2A3 (SERCA3) & $\mathrm{Ca}$ & ER/Golgi/PM & $\mathrm{E}$ \\
\hline & ATP2B1 (PMCA1) & $\mathrm{Ca}$ & PM & $\mathrm{E}$ \\
\hline & ATP2B4 (PMCA4) & $\mathrm{Ca}$ & PM & $\mathrm{E}$ \\
\hline & ATP2C1 (SPCA1) & $\mathrm{Ca}, \mathrm{Mn}$ & Golgi & $\mathrm{E}$ \\
\hline & ATP13A1 & $\mathrm{Mn}$ (putative) & $E R$ & $\mathrm{E}$ \\
\hline & ATP13A4 & $\mathrm{Mg}, \mathrm{Mn}, \mathrm{Ca}$ (putative) & Endos. & $\mathrm{E}$ \\
\hline \multirow[t]{10}{*}{$\underline{\text { IIP }}$} & SLC39A1 (ZIP1) & $\mathrm{Zn}$ & PM & । \\
\hline & SLC39A3 (ZIP3) & $\mathrm{Zn}$ & PM & । \\
\hline & SLC39A6 (ZIP6) & $\mathrm{Zn}$ & PM & । \\
\hline & SLC39A7 (ZIP7) & $\mathrm{Zn}$ & ER/Golgi & I \\
\hline & SLC39A8 (ZIP8) & $\mathrm{Mn}, \mathrm{Zn}, \mathrm{Fe}, \mathrm{Cd}$ & PM & । \\
\hline & SLC39A9 (ZIP9) & $\mathrm{Zn}$ & Golgi & । \\
\hline & SLC39A10 (ZIP10) & $\mathrm{Zn}$ & PM & $\mathrm{I}$ \\
\hline & SLC39A11 (ZIP11) & $\mathrm{Zn}$ & Golgi/Nucleus & । \\
\hline & SLC39A13 (ZIP13) & $\mathrm{Zn}$ & Golgi & I \\
\hline & SLC39A14 (ZIP14) & $\mathrm{Mn}, \mathrm{Zn}, \mathrm{Fe}, \mathrm{Cd}$ & PM & i \\
\hline TFR & TFR (transferrin receptor) & $\mathrm{Mn}, \mathrm{Fe}$, other metals & PM & I \\
\hline
\end{tabular}




$\begin{array}{ll}\text { Name of } & \text { Main clinical } \\ \text { disease or } & \text { phenotype(s) } \\ \text { syndrome } & \end{array}$

Main cellular \&

molecular phenotype(s)
Known defective protein(s) or external cause(s)
Causative/associated metal homeostasis disturbances

\begin{tabular}{|c|c|c|c|c|c|}
\hline $\begin{array}{l}\text { Alzheimer's disease } \\
\text { (AD) }\end{array}$ & $\begin{array}{l}\text { Neurodegeneration - cognitive } \\
\text { disorders }\end{array}$ & $\begin{array}{l}\text { Increased amyloid } \beta \text { protein } \\
\text { production/deposition in brain }\end{array}$ & $\begin{array}{l}\beta \text {-amyloid precursor protein - } \\
\text { apoE - presenilin-1 - } \mathrm{Na}: \mathrm{Ca} \\
\text { exchangers ( } \mathrm{NCX} \text { family) }\end{array}$ & $\begin{array}{l}\text { Abnormal distribution of } \mathrm{Cu}, \mathrm{Fe}, \mathrm{Zn} \& \\
\mathrm{Mn} \text { in brain - impaired } \mathrm{Ca} \\
\text { homeostasis }\end{array}$ & $\begin{array}{l}{[79-81} \\
93,94]\end{array}$ \\
\hline $\begin{array}{l}\text { Acrodermatitis } \\
\text { enteropathica } \mathrm{Zn} \text { - } \\
\text { deficiency disease }\end{array}$ & $\begin{array}{l}\text { Diarrhea - dermatitis - failure to } \\
\text { thrive }\end{array}$ & Not reported & SLC39A4 (ZIP4) & Low serum $\mathrm{Zn}$ concentration & [102] \\
\hline $\begin{array}{l}\text { Cancer metastasis in } \\
\text { lymph nodes }\end{array}$ & $\begin{array}{l}\text { Metastatic spread to the lymph } \\
\text { nodes }\end{array}$ & Not reported & SLC39A6 (ZIP6) & Low serum $\mathrm{Zn}$ concentration & [102] \\
\hline Carotid artery disease & $\begin{array}{l}\text { Carotid artery stenosis - impaired } \\
\text { integrity of endothelial cells }\end{array}$ & Not reported & SLC39A2 (ZIP2) & Low serum $\mathrm{Zn}$ concentration & [102] \\
\hline Darier's disease & $\begin{array}{l}\text { Skin disorder (acantholytic } \\
\text { dyskeratose)-sometimes mild } \\
\text { mental illnesses }\end{array}$ & $\begin{array}{l}\text { Abnormal desmosome-keratin } \\
\text { filament complex - keratinocyte } \\
\text { adhesion breakdown - impaired } \\
\text { actin reorganization }\end{array}$ & ATP2A2 (SERCA2) & Cellular Ca homeostasis disturbance & [97] \\
\hline $\begin{array}{l}\text { Familial hypocalciuric } \\
\text { hypercalcemia (FHH) }\end{array}$ & $\begin{array}{l}\text { Hypercalcemia - usually } \\
\text { asymptomatic }\end{array}$ & Not reported & Ca-sensing receptor (CasR) & $\begin{array}{l}\text { Increased serum Ca concentration \& } \\
\text { low urinary Ca excretion }\end{array}$ & [95] \\
\hline Hailey-Hailey disease & $\begin{array}{l}\text { Skin disorder (acantholytic } \\
\text { dyskeratose) }\end{array}$ & Similar to Darier's disease & ATP2C1 (SPCA1) & Cellular Ca homeostasis disturbance & [98] \\
\hline $\begin{array}{l}\text { Huntington's } \\
\text { syndrome }\end{array}$ & $\begin{array}{l}\text { Neurodegeneration - motor \& } \\
\text { cognitive disorders }\end{array}$ & $\begin{array}{l}\text { Accumulation \& clustering of } \\
\text { abnormal huntingtin protein }\end{array}$ & Huntingtin & $\begin{array}{l}\text { Low levels of } \mathrm{Mn} \text { in neuronal cells and } \\
\text { the striatum }\end{array}$ & [78] \\
\hline $\begin{array}{l}\text { Hyperostosis cranialis } \\
\text { interna }\end{array}$ & $\begin{array}{l}\text { Bone disorder (intracranial bone } \\
\text { overgrowth at the skull) }\end{array}$ & $\begin{array}{l}\text { Hyper-activation of CAMP-CREB \& } \\
\text { NFAT signaling }\end{array}$ & SLC39A14 (ZIP14) & Cellular $\mathrm{Zn}$ accumulation & [102] \\
\hline $\begin{array}{l}\text { Hypermanganesaemia } \\
\text { with dystonia I \& } 2\end{array}$ & $\begin{array}{l}\text { Weak cognititve impairment - } \\
\text { liver disease - Polycythaemia }\end{array}$ & Not reported & $\begin{array}{l}\text { SLC30A10 (ZnT10) - Type } 1 \\
\text { SLC39A14 (ZIP14) - Type } 2\end{array}$ & $\begin{array}{l}\text { Low serum Mn concentration - } \\
\text { Depletion of iron stores }\end{array}$ & [85] \\
\hline $\begin{array}{l}\text { Kufor-Rakeb } \\
\text { syndrome }\end{array}$ & $\begin{array}{l}\text { Neurodegeneration - motor } \\
\text { disorders \& dementia }\end{array}$ & $\begin{array}{l}\text { Lysosomal \& mitochondrial } \\
\text { dysfunctions }\end{array}$ & $\begin{array}{l}\text { ATP13A2 (PARK9) (possibly } \\
\text { causing indirect effects on } \\
\text { metal homeostasis [see text) }\end{array}$ & $\begin{array}{l}\text { Altered cellular } \mathrm{Mn} \& \mathrm{Zn} \text { homeostasis } \\
\text { - casual Fe accumulation in brain } \\
\text { caudate \& putamen }\end{array}$ & [89] \\
\hline Leigh-like syndrome & $\begin{array}{l}\text { Neurological disorder } \\
\text { characterized by a progressive } \\
\text { psychomotor regression }\end{array}$ & $\begin{array}{l}\text { Defects in mitochondrial energy } \\
\text { production }\end{array}$ & SLC39A8 (ZIP8) & $\begin{array}{l}\text { Low serum \& high urine } \\
\text { concentrations of } \mathrm{Mn}\end{array}$ & [140] \\
\hline Manganism & $\begin{array}{l}\text { Neurological disorders resembling } \\
\text { PD symptoms }\end{array}$ & $\begin{array}{l}\text { Mitochondrial dysfunction - release } \\
\text { of ROS - altered neurotransmitter } \\
\text { metabolism \& release }\end{array}$ & $\begin{array}{l}\text { Chronic environmental } \\
\text { exposure to } \mathrm{Mn}\end{array}$ & $\begin{array}{l}\text { Increased systemic \& cellular } \mathrm{Mn} \\
\text { concentrations }\end{array}$ & [82] \\
\hline $\begin{array}{l}\text { Metastasis of breast } \\
\text { cancer }\end{array}$ & $\begin{array}{l}\text { Breast cancer invasion \& } \\
\text { metastasis }\end{array}$ & Not reported & SLC39A10 (ZIP10) & Low serum $\mathrm{Zn}$ concentration & [102] \\
\hline $\begin{array}{l}\text { Neonatal severe } \\
\text { hyperparathyroidism } \\
\text { (NSHPT) }\end{array}$ & $\begin{array}{l}\text { Hypercalcemia - } \\
\text { hyperparathyroidism - bone } \\
\text { demineralization - failure to } \\
\text { thrive - neurodevelopmental } \\
\text { disorders }\end{array}$ & Not reported & Ca-sensing receptor (CasR) & Elevated serum Ca concentration & [95] \\
\hline $\begin{array}{l}\text { Parkinson's disease } \\
\text { (PD) }\end{array}$ & $\begin{array}{l}\text { Neurodegeneration - motor \& } \\
\text { cognitive disorders }\end{array}$ & $\alpha$-synuclein within Lewy bodies & $\begin{array}{l}\text { SNCA - LRRK2 - EIF4G1 - VPS35 } \\
\text { PARK2 - PINK1 - PARK7 - plus } \\
\text { others including SLC30A10 }\end{array}$ & Altered $\mathrm{Fe}, \mathrm{Mn} \& \mathrm{Zn}$ homeostasis & $\begin{array}{l}{[80,81,} \\
87]\end{array}$ \\
\hline SLC39A8-CDG & $\begin{array}{l}\text { Delayed psychomotor } \\
\text { development - hypotonia - short } \\
\text { stature - seizures - visual } \\
\text { impairment \& cerebellar atrophy }\end{array}$ & Impaired glycosylation & SLC39A8 (ZIP8) & $\begin{array}{l}\text { Low serum \& high urine } \mathrm{Mn} \\
\text { concentrations }\end{array}$ & [112] \\
\hline $\begin{array}{l}\text { Spondylocheiro } \\
\text { dysplastic form of } \\
\text { Ehlers-Danlos } \\
\text { syndrome }\end{array}$ & $\begin{array}{l}\text { Short stature - skin, joints \& eyes } \\
\text { abnormalities }\end{array}$ & Underhydroxylation of collagen & SLC39A13 (ZIP13) & $\begin{array}{l}\text { Low serum \& cellular } \mathrm{Zn} \\
\text { concentrations }\end{array}$ & [102] \\
\hline TMEM165-CDG & $\begin{array}{l}\text { Mental \& growth retardation - } \\
\text { strong bone \& cartilage dysplasia } \\
\text { - muscular hypertrophy - excess } \\
\text { fat production - increased serum } \\
\text { transaminases \& LDH, decreased } \\
\text { coagulation factors }\end{array}$ & Impaired glycosylation & TMEM165 & $\begin{array}{l}\text { Disturbances in intracellular } \mathrm{Mn} \mathrm{\&} \mathrm{Ca} \\
\text { homeostasis }\end{array}$ & [111] \\
\hline XMEN disease & $\begin{array}{l}\text { Impairment of T-cell immune } \\
\text { functions }\end{array}$ & $\begin{array}{l}\text { Abolition of the transient T-cell } \\
\text { receptor-induced } \mathrm{Mg} \text { flux required } \\
\text { for optimal T-cell activation }\end{array}$ & $\begin{array}{l}\text { MAGT1 (possibly impairing } \\
\text { glycosylation of protein(s) } \\
\text { involved in Mg transport) }\end{array}$ & $\begin{array}{l}\text { Chronic decrease in the intracellular } \\
\text { basal level of free } \mathrm{Mg}\end{array}$ & [115] \\
\hline
\end{tabular}




\section{Table 3 (Foulquier \& Legrand)}

\begin{tabular}{|c|c|c|c|c|c|}
\hline $\begin{array}{l}\text { Gene } \\
\text { mutation(s }\end{array}$ & Type of mutation(s) & Protein change(s) & $\begin{array}{l}\text { Age of patients at } \\
\text { the date of report }\end{array}$ & Clinical phenotypes & Ref. \\
\hline c. $792+182 G>A$ & $\begin{array}{l}\text { Homozygous - activation of a } \\
\text { cryptic splice donor site }\end{array}$ & $\begin{array}{l}\text { Production of } 2 \text { different } \\
\text { proteins: wild-type one \& } \\
\text { truncated protein with } 27 \text { aa } \\
\text { change at the C-terminal part }\end{array}$ & $\begin{array}{l}3 \text { patients : the first of } 2 \\
\text { siblings died at the age of } 14 \\
\text { months while the second } \\
\text { one was } 19 \text { years old - the } \\
\text { third patient was } 9 \text { years old }\end{array}$ & $\begin{array}{l}\text { Severe growth retardation \& failure to thrive - } \\
\text { skeletal and facial dysplasia, osteoporosis - } \\
\text { brain \& neurological abnormalities : } \\
\text { microcephaly, convulsions, muscular } \\
\text { hypotonia, joint laxity \& eye abnormalities - } \\
\text { hepatomegaly - feeding problems - blood } \\
\text { abnormalities : thrombopenia \& creatine } \\
\text { kinase elevations }\end{array}$ & [111] \\
\hline c. $377 G>A$ & $\begin{array}{l}\text { Homozygous - } 1 \text { missense } \\
\text { mutation }\end{array}$ & Arg126His & $>9$ years old & $\begin{array}{l}\text { Mild growth retardation dysmorphy - muscular } \\
\text { hyponia, hepatomegaly - thrombopenia - renal } \\
\text { abnormality (haemolytic uremic syndrome) - } \\
\text { blood creatine kinase elevations }\end{array}$ & [111] \\
\hline $\begin{array}{l}\text { c. } 377 C>T \& \\
\text { c. } 910 G>A\end{array}$ & $\begin{array}{l}\text { Compound heterozygous - } 2 \\
\text { missense mutations }\end{array}$ & Arg126Cys \& Gly304Arg & Not precised & $\begin{array}{l}\text { Mild growth retardation - failure to thrive - } \\
\text { dysmorphy - skeletal dysplasia - eye } \\
\text { abnormalities }\end{array}$ & [111] \\
\hline c.323 A>G & $\begin{array}{l}\text { Homozygous - } 1 \text { missense } \\
\text { mutation }\end{array}$ & Glu108Gly & $\begin{array}{l}2 \text { siblings both died at the } \\
\text { age of } 5 \text { months }\end{array}$ & $\begin{array}{l}\text { Facial dysmorphism - cardiac defects : apical } \\
\text { muscular ventricular septal defects, patent } \\
\text { foramen ovale, small patent ductus arteriorus } \\
\& \text { small right ventricular hypertrophy - brain } \\
\text { abnormalities : enlarged lateral \& third brain } \\
\text { ventricles - neurological abnormalities : large, } \\
\text { temporarily tensed fontanel, muscular } \\
\text { hypertonia - respiratory distress - proteinuria } \\
\text { causing nephrotic syndrome \& renal failure }\end{array}$ & [163] \\
\hline
\end{tabular}


Figure 1 (Foulquier \& Legrand)

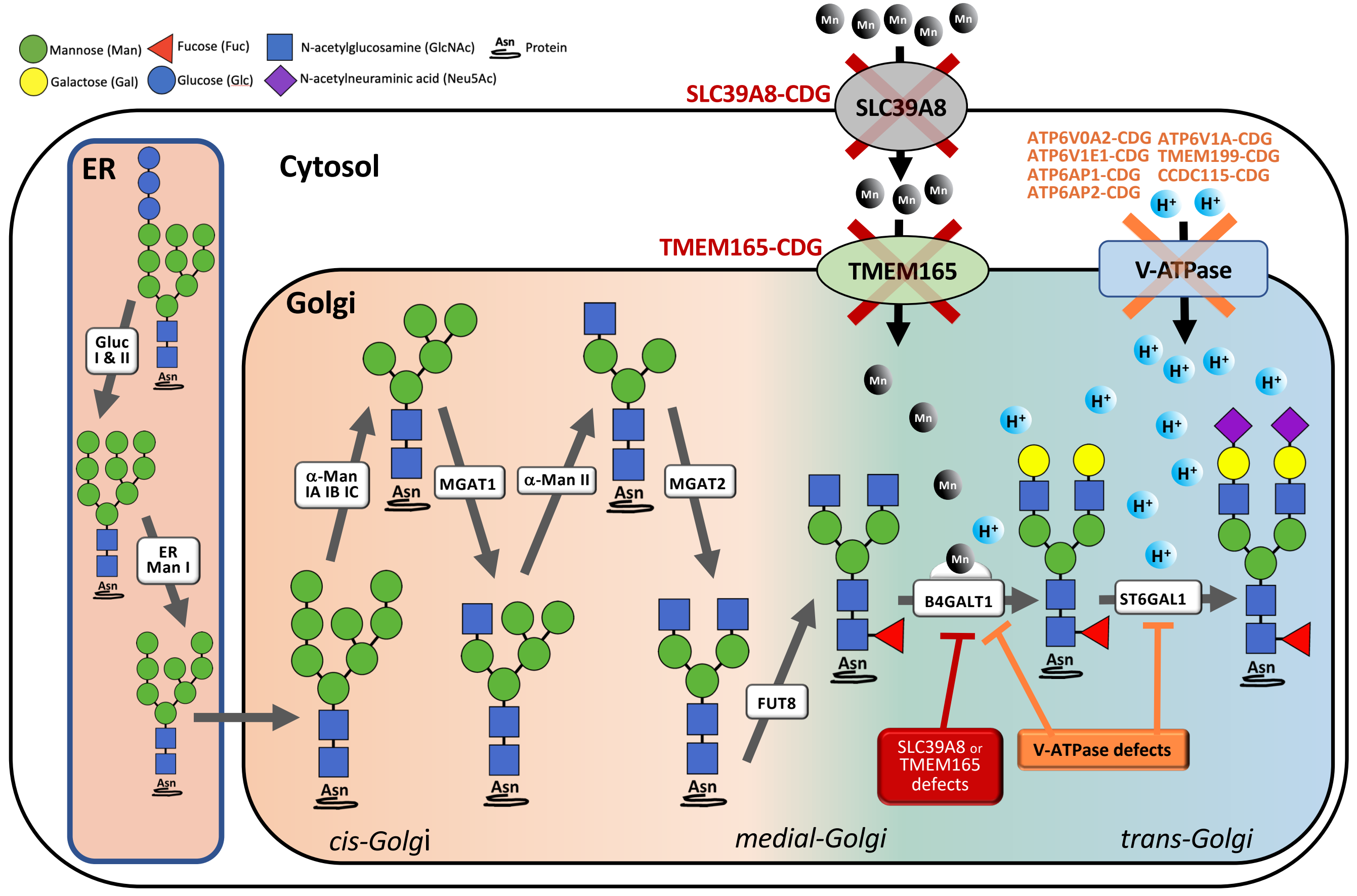


CDF (P)

Nuclear pores (solutes \& proteins)

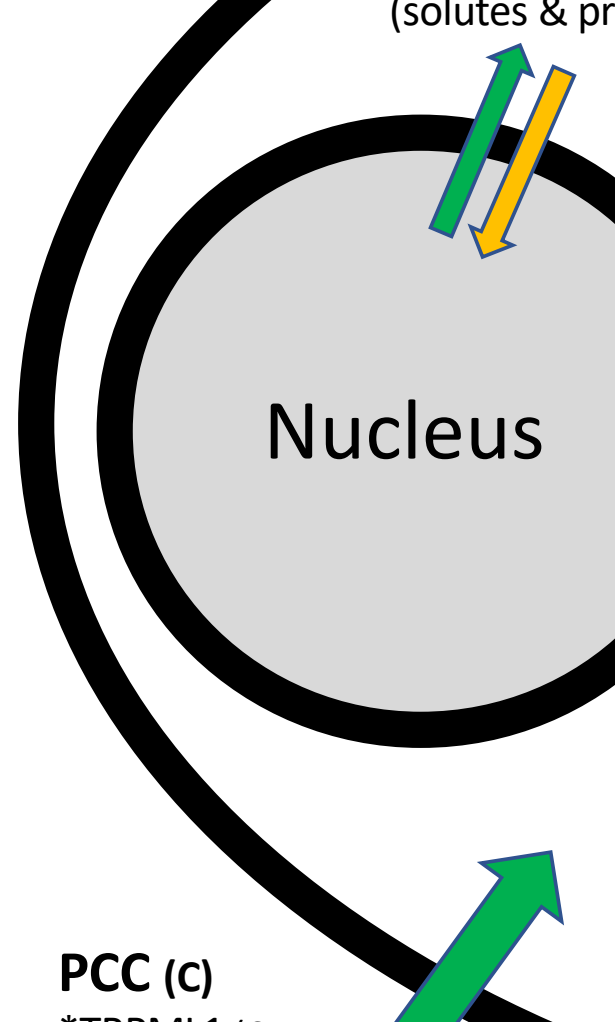

*TRPML1 (Ca, Zn, $\mathrm{Fe}, \mathrm{Mn}$, n. sel.)

VIC (VGCC) (C) CACNA1H (Ca, Mn, $\mathrm{Fe}, \mathrm{Cd}$ )

\section{RP-CC (C)}

TRPM7 (Ca, Mg, Zn, Mn,

n. sel.)
FPN (P)

SLC4OA1 (Mn,

$\mathrm{Fe}, \mathrm{Co}, \mathrm{Zn}, \mathrm{Cu}$ )

\section{NRAMP (P)}

*SLC11A1 (Mn, Fe) *SLC11A2 (Mn, Fe, PCC (C) $\mathrm{Zn}, \mathrm{Cu}, \mathrm{Cd}, \mathrm{Co}, \mathrm{Ni})$ TRPML1 (Ca,

\section{CaCA2 (P) P-ATPase (P)}

TMEM165 ATP2C1 (Ca, Mn)

(Mn, Ca) *ATP2A2 (Ca (Mn))

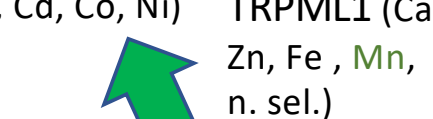

$4 \begin{aligned} & \mathrm{Zn}, \mathrm{Fe}, \mathrm{Mn} \text {, } \\ & \text { n. sel.) }\end{aligned}$

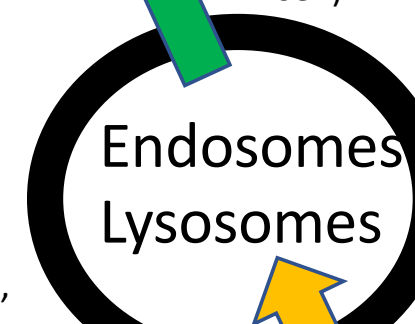

${ }^{*} \mathrm{SLC11A2}(\mathrm{Mn}$

$\mathrm{Fe}, \mathrm{Zn}, \mathrm{Cu}, \mathrm{Cd}$,

$\mathrm{Co}, \mathrm{Ni}, \mathrm{Pb}$ )
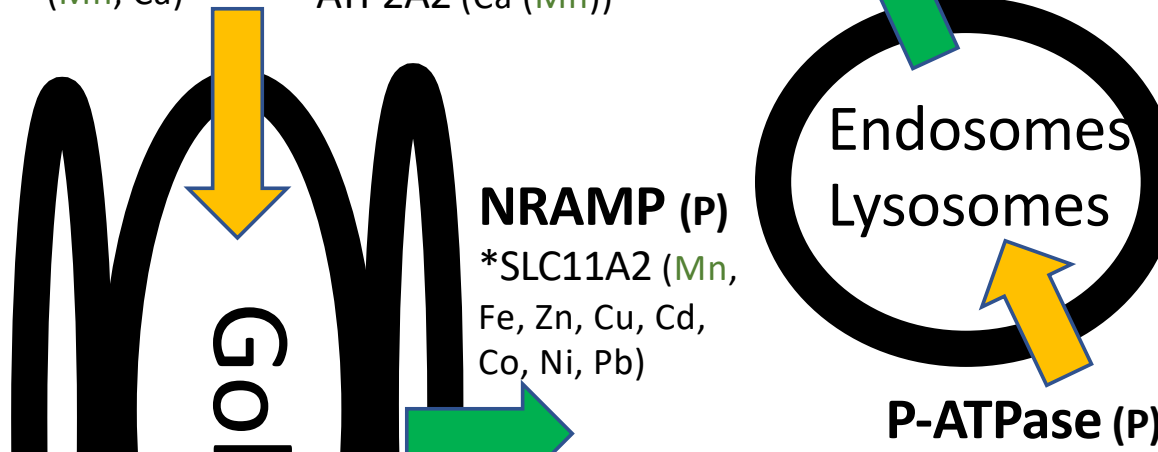

CaCA2 (P)

*TMEM165

\section{P-ATPase (P)}

ATP13A4 (Mg, Mn, Ca)

(putative)

\section{NRAMP (P)}

*SLC11A2 (Mn, Fe,

$\mathrm{Zn}, \mathrm{Cu}, \mathrm{Cd}, \mathrm{Co}, \mathrm{Ni}, \mathrm{Pb}$ )

\section{P-ATPase (P)}

ATP2A2 (Ca (Mn))

ATP13A1 (Mn) (putative)

$>$

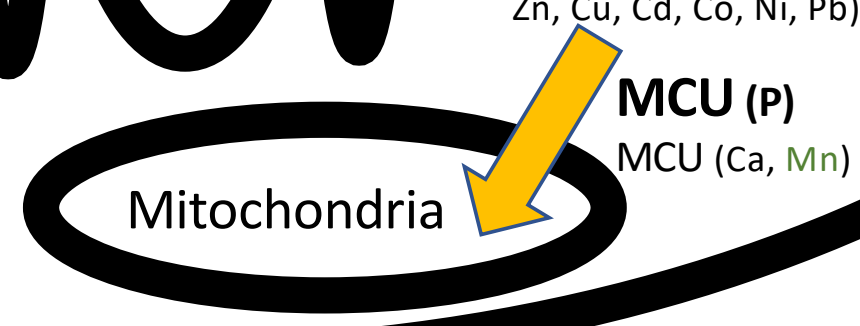

NRAMP (P)

SLC11A1 (Mn, Fe) TFR

SLC11A2 (Mn, Zn, TFR (Fe, Mn,

$\mathrm{Fe}, \mathrm{Cu}, \mathrm{Cd}), \mathrm{Co}, \mathrm{Ni}$ ) other biometals)
SLC39A8 (Mn, Zn,

$\mathrm{Fe}, \mathrm{Cd})$

SLC39A14 (Mn,

$\mathrm{Zn}, \mathrm{Fe}, \mathrm{Cd})$ 
Figure 3 (Foulquier \& Legrand)

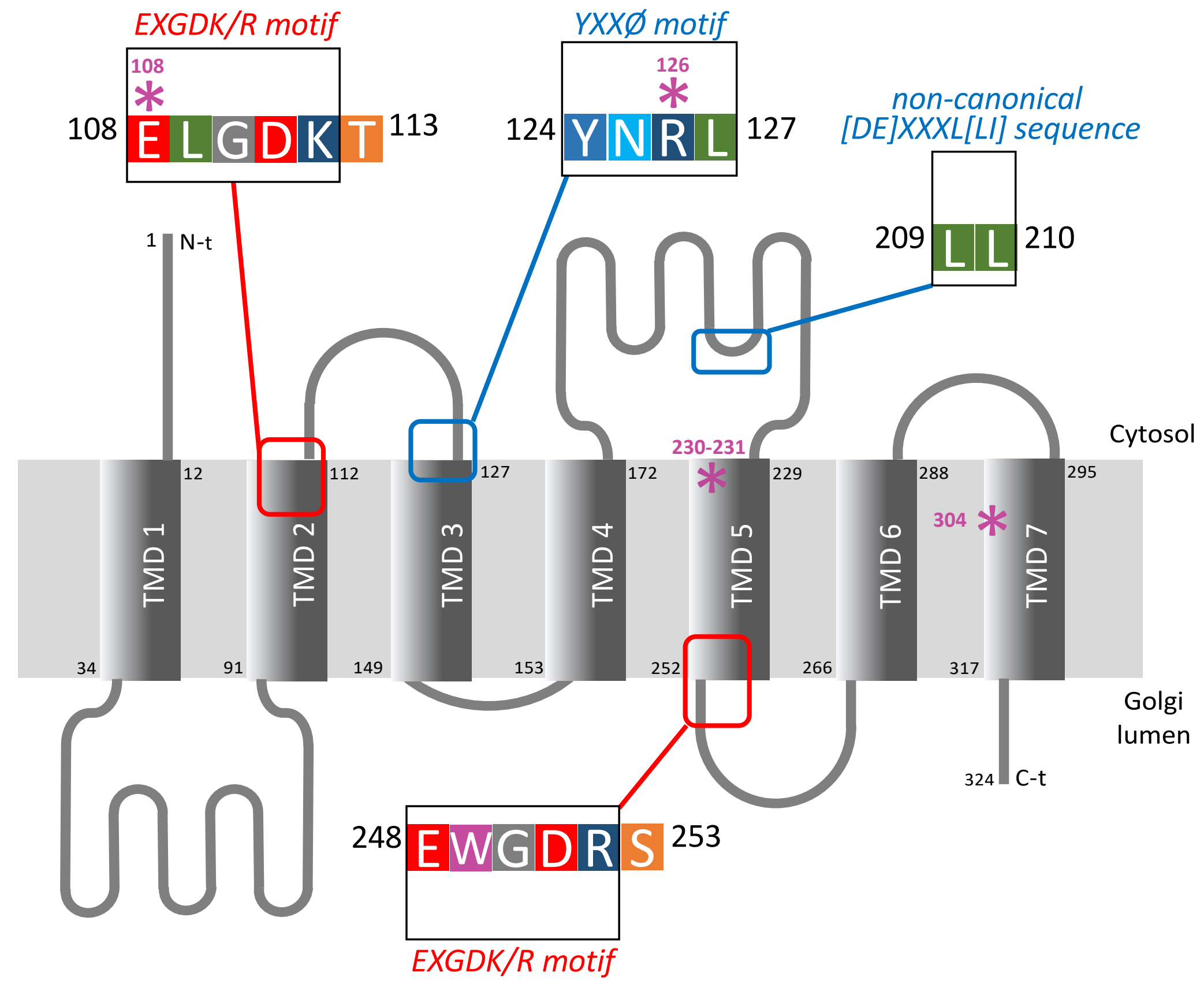


Figure 4 (Foulquier \& Legrand)

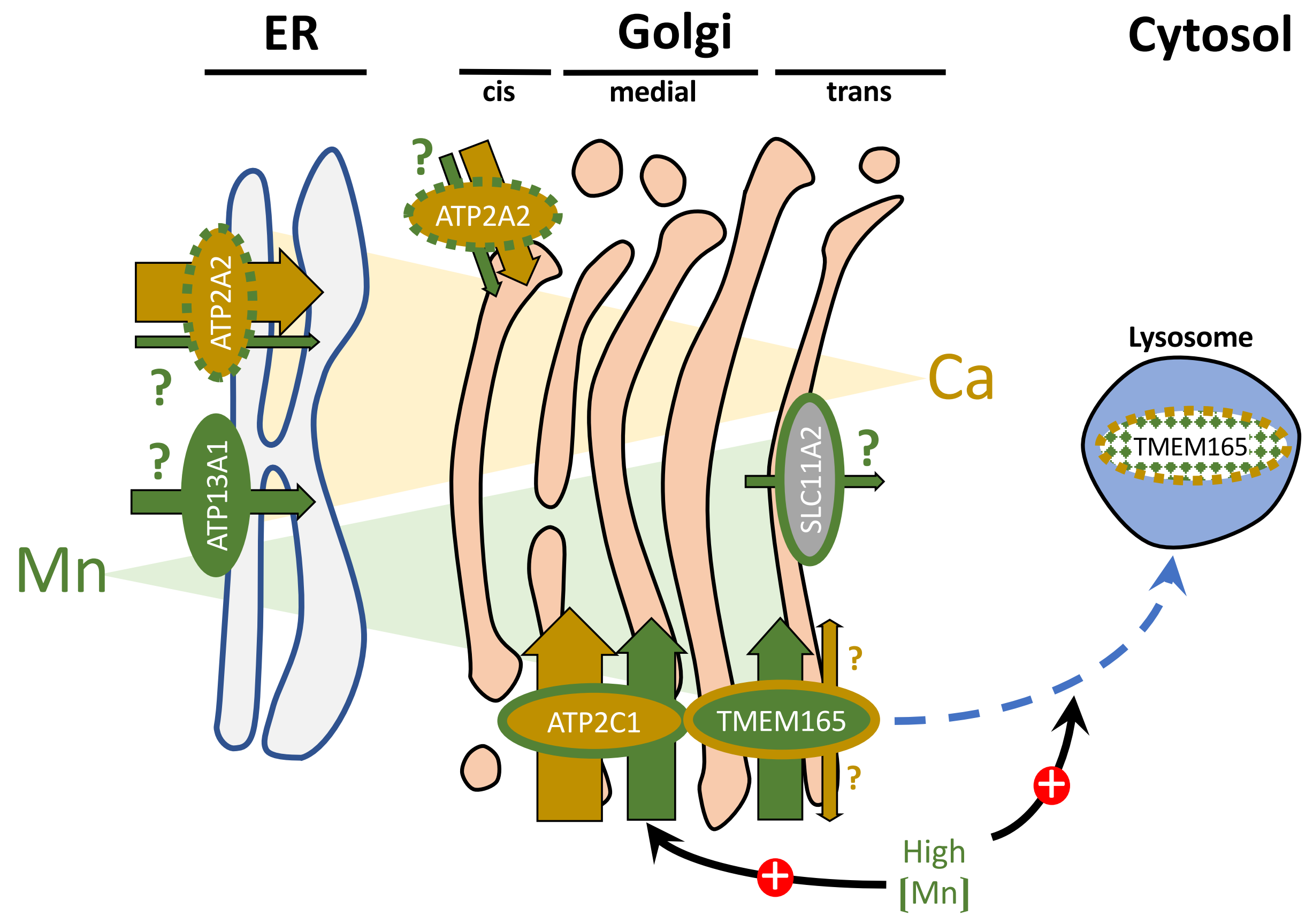

